\title{
La gestión de los conflictos estudiantiles: un enfoque desde la administración de la educación
}

\section{Student Conflict Management: an Approach from Educational Administration}

Recibido 30 octubre 2012 • Aceptado 25 mayo 2012 • Corregido 10 junio 2012

\author{
Armando Chacón Mora ${ }^{1}$ \\ armachacon@gmail.com
}

Ministerio de Educación Pública

\begin{abstract}
Resumen. El personal directivo de las instituciones educativas debe constituirse en un recurso para lograr procesos de mediación entre los diferentes acontecimientos que se presenten tanto a lo interno como a lo externo de la institución, así como gestionar las acciones inherentes a sus funciones y liderar al grupo en la consecución de los objetivos propuestos. Esto requiere de parte del personal directivo de las organizaciones educativas de una serie de competencias, que no solo deben ser las que comúnmente se estipulan en relación con la planeación, la dirección, ejecución y evaluación institucional, sino también aquellas concernientes a la prevención y construcción de diversas estrategias que ayuden a toda la comunidad educativa a prevenir y minimizar situaciones de conflictos estudiantiles y de la violencia que atenten con el proceso educativo. Este artículo se fundamenta en una investigación de tipo cualitativo realizada durante el año 2010, en una institución de educación secundaria pública de la Provincia de San José, Costa Rica. La información se obtuvo por medio de entrevistas, grupos focales y la observación. Esta información fue suministrada por los estudiantes, docentes y el personal directivo del Liceo. En conclusión la investigación determinó la necesidad que poseen las instituciones educativas de un plan para la prevención e intervención de los conflictos estudiantiles en el contexto actual.
\end{abstract}

Palabras Claves. Conflictos y violencia, conflictos estudiantiles, gestión de los conflictos, administración de la educación, prevención de los conflictos estudiantiles, conflictos en las organizaciones educativas, organizaciones educativas.

Abstract. The administrative staff of educational institutions must become a resource to achieve mediation processes between different events both internally and externally of the institution. This staff will manage inherent actions in their duties and leads the group in achieving objectives. This requires from personnel skills that are not part of the ones related to planning,

1 Doctor en Educación de la Universidad Católica de Costa Rica. Magíster en Ciencias de la Educación con énfasis en Administración Educativa de la Universidad de Costa Rica. Licenciado en Filosofía de la Universidad Pontificia Católica y Maestra Santo Domingo, República Dominicana; reconocido por la Universidad de Costa Rica (UCR). Actualmente labora como director del Liceo Experimental Bilingüe de la Trinidad de Moravia. 
management, and institutional assessment, but also those concerning prevention and construction of strategies to help school community in order to prevent and minimize student conflicts and violence that threaten educational process. This article is based on a qualitative study conducted in a public institution of higher education in San José, Costa Rica, in 2010. This information was gathered through interviews, focus groups and observation. The information was provided by students, teachers and managers of the high school institution. In conclusion, this research determined the need of a plan for preventing and intervening in student conflicts educational institutions.

Keywords. Conflict and violence, student conflicts, conflict management, education administration, student conflict prevention, conflict in educational organizations, educational organizations.

\section{Introducción}

El contexto en el cual se encuentran inmersas las organizaciones educativas, es complejo; ante esta realidad las mismas organizaciones están con una serie de transformaciones en sus estructuras. Se requiere que los sujetos involucrados en la institución educativa adquieran nuevas competencias que lo integren de forma rápida y constante, para que se logre una adaptación en el entorno cambiante.

Las organizaciones, por lo tanto, deben ir sistematizando sus procesos de cambio, rediseñando sus modelos y estructuras, de tal forma que respondan y se adapten a los nuevos entornos y exigencias que la sociedad del conocimiento y de la información exigen. Las instituciones educativas deben desarrollar actividades enfocadas a prever los periodos críticos y a dirigir los cambios que estas crisis exigen. Deben aprender a ser flexibles ante los nuevos retos, las nuevas variables y exigencias de la sociedad del conocimiento. Al respecto Fernández (2008, p.25) expone, "por tanto las instituciones tienen que gestionar sus conocimientos para mantenerse vivas (...) su saber hacer es lo que les va a permitir innovar, y con la innovación perdurar".

Ante esta realidad, la administración de la educación debe brindar respuestas ante estos desafíos y adaptarse a los cambios que el nuevo modelo económico social emergente requiere. Esto significa en el campo administrativo, un replanteamiento de sus modos y usos habituales de actuar, en los que según George y Alvarez (2005, p.259) "se incorporaron diferentes conceptos, nuevas variables y se modificaron los enfoques de análisis para dar respuesta a los retos que les planteaba el cambio". 
La sociedad denominada como postmoderna, poscapitalista o neoliberal, ejerce su influencia en el modo de ser y actuar de las personas, en sus comportamientos, costumbres, valores y actitudes. Estas nuevas pautas de comportamiento se manifiestan especialmente en la población infantil y juvenil que estudia en los centros educativos. Ante esta realidad la misión de las organizaciones educativas es compleja, como lo expone Morín (2001, p.42) “(..) la educación debe promover una "inteligencia general" apta para referirse, de manera multidimensional, a lo complejo, al contexto en una concepción global".

Este nuevo milenio exige a las organizaciones educativas la construcción de propuestas viables para reivindicar a las personas, por medio de la movilidad social y luchar contra la exclusión social, que trae como consecuencia un aumento de la pobreza, la delincuencia y los conflictos estudiantiles. Este tipo de problemáticas son las que interesan desde las organizaciones educativas.

Ante este contexto, el tema de los conflictos escolares y colegiales ha sido objeto de múltiples estudios e investigaciones. Exploraciones en el campo educativo han llegado a la conclusión de que las diversas teorías curriculares, enfoques metodológicos, y evaluaciones, no ofrecen una suficiente explicación de las diversas problemáticas del siglo XXI.

En lo que respecta a los conflictos estudiantiles, el papel del director y la directora en las organizaciones educativas es fundamental, por ser ellos la máxima autoridad de la institución, tienen el compromiso de construir espacios de reflexión para la disminución paulatina de este tipo de fenómenos, y la prevención de los mismos. Además, es responsabilidad del personal directivo intervenir en los procesos, sin que estos trasgredan los derechos fundamentales de las personas, en especial las de la población estudiantil, personal docente y administrativo.

\section{Referente teórico}

\section{Contexto en que se desarrollan las organizaciones educativas actuales.}

Una de las medidas de contingencia ante los conflictos estudiantiles que a nivel educativo y disciplinario se ha tomado en las organizaciones educativas, son la renovación de los reglamentos, sanciones y sus efectos tanto normativos como reproductivos en el funcionamiento institucional y en la comunidad estudiantil. El rol que juega la administración de la educación ante estas situaciones es fundamental. 


\section{Giesesion:

[Número publicado el 30 de J unio del 2012]
Revista Cientifica Digital ISSN:2215-2288

URL:http:// revista dig ita l.ea e.fc s.uc r.ac.cr/

La administración de la educación, debe proponer alternativas diversas y coherentes que respondan a los retos que el nuevo siglo demanda. Estos retos se manifiestan en el campo social, cultural y sobre todo generacional. Esta es una de las razones que a criterio con Delors (1996), plantea la necesidad de realizar cambios urgentes en las estructuras administrativas y curriculares de las organizaciones educativas para este siglo XXI. Este informe es de mucha relevancia en lo que concierne al campo administrativo y educativo, pues este se constituye en un importante insumo, dentro de los procesos de variaciones administrativas y curriculares que deben realizar las organizaciones educativas actuales. Como lo estipula Delors (1996), estos cambios estructurales y curriculares deben gestionarse a partir de cuatro pilares: aprender a conocer; aprender a ser; aprender a hacer; aprender a vivir juntos, aprender a vivir con los demás. Estos pilares de acuerdo con De Felippis (2004), deben ser los cimientos sobre los cuales los sistemas administrativos y curriculares deben apoyarse, sobre todo en el contexto dentro del cual están insertas las organizaciones educativas en la actualidad. Al respecto plantea:

La educación en algunas circunstancias actúa en un medio violento, producto de las interacciones sociales a las que se enfrenta, y llega a veces a límites extremos, como cuando los alumnos portan armas en las escuelas, los padres están armados por medidas de seguridad [...] ¿Qué hace el docente frente a estas situaciones? ¿Qué puede hacer? [...] la educación es el tema de hoy y de todos los tiempos; va más allá de un objeto académico, es la pieza que engarza las mutaciones que encierra la sociedad y su cultura. (p. 13)

Aceptar estos retos representa para las autoridades educativas nacionales y para las universidades, la formación de profesionales con las competencias necesarias para enfrentar los diversos problemas sociales, sobre todo en lo que compete al ámbito conductual conflictivo. Otras situaciones sociales del entorno a las que deben enfrentarse los (as) profesionales de la educación, están relacionadas a las drogas, la deformación de los valores, los conflictos y la violencia estudiantil.

Ante este panorama, las políticas económicas han favorecido el aumento de la polarización social. Estas desigualdades se manifiestan con la subida creciente de los índices de pobreza, que al mismo tiempo provoca un efecto dominó sobre las diversas problemáticas 
sociales, destacándose entre estas los conflictos sociales. Estos conflictos pueden llegar inclusive hasta la violencia tanto a lo interior como a lo exterior de las organizaciones educativas.

Es importante considerar en el momento de realizar un análisis de los diferentes fenómenos relacionados con los conflictos en las organizaciones educativas nacionales, el tipo de abordaje de estos. Es relevante que se aborden a partir de un enfoque holístico e interdisciplinario, dentro del cual no solo sean objeto de estudio los niños y las niñas y los adolescentes que muestran conductas conflictivas y violentas, sino también, sus familias y su situación socioeconómica. Entre otros agentes que deben tomarse en cuenta para el análisis son las instituciones como la familia, los medios de comunicación, las pandillas juveniles y el contexto en el cual se encuentran las organizaciones educativas.

La familia en este contexto, se constituye en un elemento importante a considerar, sobre todo por constituirse en la primera escuela de formación de valores, tanto para los niños, las niñas y la población juvenil. Son numerosos los ejemplos que se encuentran en los centros educativos relacionados con los conflictos y la violencia intrafamiliar, ésta en muchos casos se manifiesta en las actitudes y comportamientos de los jóvenes, los cuales han sido agredidos, heridos física y moralmente.

Otro de los aspectos que deben tomarse en cuenta a la hora de intervenir este tipo de acciones es el contexto sociodemográfico en el cual se desenvuelven los estudiantes, es la cultura organizacional de la institución a la que pertenecen. Ante este panorama las organizaciones educativas los y las profesionales de la administración de la educación tienen el deber de buscar alternativas viables, con programas y/o proyectos educativos curriculares, ante estos desafíos que la sociedad posmoderna en su complejidad les demanda.

Estas situaciones requieren de profesionales en el campo de la administración de la educación y un personal docente capaces de instruir y formar a los padres y madres de familia en las competencias necesarias para resolver las diferentes problemáticas que son causales de conflictos en sus hogares y en especial en sus progenitores. En el ámbito nacional deben abrirse espacios para la reflexión de estos temas, sobre todo la potenciación de las escuelas para padres. La familia, desde esta perspectiva se instituye en la primera fuente de formación de la persona; es fundamental dirigir los esfuerzos que sean necesarios para acompañar en la capacitación y en la toma de conciencia, con respecto de la responsabilidad que significa ser padre o madre de familia, en la actualidad. La educación en un mundo postmoderno, desde 
esta perspectiva reclama nuevas formas de pensamiento, en relación con el qué y cómo educar, "una nueva sabiduría", (Pérez, citado por Sagastizabal, 2004, p. 23), una nueva forma de repensar las estructuras, los procesos y las metodologías educativas. Esta nueva sabiduría debe encaminar a las organizaciones educativas hacia un modelo que se adecue a los desafíos que la sociedad postmoderna y la globalización demandan.

Es importante para efectos de este artículo enfatizar en los procesos de gestión inherentes a la función de los y las profesionales en la administración de la educación. A partir de estos procesos este profesional toma decisiones referentes a la buena marcha de la institución, en los aspectos relacionados con la gestión del currículo, y del recurso material y humano; la gestión que debe emanar de las direcciones debe ser líder en los procesos de toma de decisiones, fomentar el diálogo y el mejoramiento permanente; debe además, generar un clima de confianza y de escucha activa. Este proceso de gestión se caracteriza por ejecutar las acciones, transacciones y decisiones pertinentes, para realizar una gestión exitosa de los conflictos estudiantiles.

\section{Hacia una gestión exitosa de los conflictos estudiantiles.}

Una gestión exitosa por parte del personal directivo requiere de un examen profundo de la estructura escolar que administra en todos y cada uno de sus campos, ya sea el área administrativa (plan operativo, infraestructura, recursos humanos, presupuesto), como del área curricular (plan operativo, malla curricular, evaluación institucional, control interno, mejoramiento de la calidad, entre otros). Asimismo deberá tener las siguientes habilidades: capacidad organizativa y gerencial, capacidad de negociación y principalmente la inteligencia emocional básica para dirigir la organización educativa.

Estas y otras funciones directivas deben generar un ambiente de motivación, innovación y transformador tanto a lo interno, como a lo externo de las organizaciones. Para esto el personal directivo debe estar atento a los diferentes cambios que se suscitan a nivel social, cultural, fundamentalmente el organizacional, y pendiente de las diferentes transformaciones que se presenten.

Por estas razones ante este tipo de situaciones la administración de la organización educativa y su personal deben considerar en sus actividades sustantivas realizar un análisis profundo de estos entornos conflictivos. Cobra gran relevancia el estudio de estas 


\section{Giesesion: \\ Escuela de Administración Educativa}

[Número publicado el 30 de J unio del 2012]
Revista Cientifica Digital ISSN:2215-2288

URL:http:// revista dig ita l.ea e.fc s.uc r.ac.cr/

problemáticas, en la administración de la educación debe gestionarse todo un proceso que colabore con la prevención de estas situaciones conflictivas, y realizar un estudio de sus causas y sus consecuencias, de esta forma la reflexión exhaustiva de este fenómeno permite obtener un insumo para su capacitación y la del personal directivo nuevo a escala nacional. Esta capacitación desarrolla y se convierte en competencias necesarias para su formación y desempeño en la organización educativa que dirige.

\section{La educación en el siglo XXI.}

El contexto actual demanda en los y las profesionales en la administración de la educación muchos desafíos. Las políticas educativas nacionales se han de concentrar en la persona misma y en su desarrollo integral, educando en cada una de estas dimensiones esenciales, inmersas dentro de un proceso paciente, concertado, negociado y eficaz de reforma constante, que responda a las necesidades reales de la persona y de la sociedad en general.

De esta forma es urgente una reconciliación entre valores relacionados con la competencia, cooperación y la solidaridad. Por esto, de acuerdo con la Comisión de la UNESCO, sintetizada en el informe Delors (1996), deben añadirse nuevas disciplinas que fomenten el conocimiento de sí mismo; que colaboren a mantener la salud física y psicológica, y también, el aprendizaje para conocer mejor el medio ambiente natural y su conservación. La diversificación curricular y la utilización de un enfoque constructivista humanista es una tarea urgente.

A partir de un análisis profundo, relacionado con el complejo entorno en el cual están insertos los sistemas educativos, la comisión de la UNESCO insistió en establecer cuatro pilares de la educación, como un medio para así poder hacer la utopía del desarrollo personal, de toda persona y las personas, en lo que respecta a la atención de sus necesidades básicas, sobre todo en el aprendizaje.

Estos pilares de la educación, dados por la UNESCO deben constituirse en elementos trascendentales para el mejoramiento de la administración de la educación, en lo que respecta a una auténtica formación integral del ser humano y marcan las pautas para la prevención de diferentes tipos de conductas antisociales, al mismo tiempo, se convertirán en fundamentos para la propuestas de intervención y prevención en el tema de conflictos estudiantiles. Según Delors (1996), estos cinco pilares deben ser: 
Aprender a vivir juntos: (saber vivir juntos en las comunidades a las que pertenecemos). Aquí se trata de ir conociendo mejor a los demás, su historia y sus tradiciones y su espiritualidad, para así ir creando un espíritu nuevo que impulse la realización de proyectos comunes o la solución inteligente y pacífica de conflictos, comprendiendo que las relaciones de interdependencia son cada vez mayores y que hay que hacer una análisis compartido de los retos y los riesgos. Esta comisión plantea que la educación ha de generar un espíritu nuevo, para así poder convertir la utopía en realidad de aprender a vivir juntos.

Este aprendizaje se constituye en una de las principales empresas de la educación contemporánea, ya que estamos envueltos en un ambiente hostil, caracterizado por las guerras, la violencia y la agresión, es decir, en un ambiente conflictivo, que genera personas conflictivas. Pero no solamente estas son formas de violencia, la competencia industrial y económica vigente, el éxito individual, es decir, la ofensiva económica despiadada y desigual entre los diferentes grupos, empresas y naciones. Al respecto, Delors (1996) lo expone así:

En consecuencia, en sus programas la educación escolar debe reservar tiempo y ocasiones suficientes para iniciar desde muy temprano a los jóvenes en proyectos cooperativos, en el marco de actividades deportivas y culturales y mediante su participación en actividades sociales: renovación de barrio, ayuda a los más desfavorecidos, acción humanitaria, servicios de solidaridad entre las generaciones. ( $p$. 117)

Aprender a conocer: esto hace referencia al papel que juega la educación dentro de un mundo que se encuentra en constantes cambios derivados de los avances de la ciencia y las nuevas formas de actividades económicas y sociales. Esto consiste para cada persona en aprender a comprender el mundo que le rodea, para así poder vivir con dignidad, desarrollando sus capacidades profesionales y comunicándose con los demás. Adicionalmente implica acceso a los conocimientos científicos suficientes, la apertura a otras lenguas y conocimientos para lograr este cometido.

Aprender a conocer supone aprender a aprender, ejercitando la memoria y el pensamiento, en la combinación de los métodos inductivo y deductivo para una adecuada concatenación del pensamiento, se debe enseñar que el aprendizaje no acaba nunca y que es 
para toda la vida. Se ha de compaginar por lo tanto, una cultura general con una gran amplitud, para así tener la posibilidad de estudiar a fondo un número reducido de materias.

Aprender a hacer: esto según el documento de la UNESCO, consiste en la no limitación de la capacidad que tiene el ser humano de conseguir y lograr metas. Se trata de adquirir las competencias necesarias que le permitan al ser humano hacer frente a las diversas situaciones que se le presenten y que le puedan facilitar el trabajo en equipo. Esto se logra en una mejor medida si los estudiantes tienen una opción y cuentan con la posibilidad de evaluarse y de enriquecerse, por medio de la participación en actividades profesionales o sociales de forma paralela a sus estudios, alternado así escuela y trabajo.

En el fondo consiste en ayudar al estudiante a poner en práctica su conocimiento y adaptar la enseñanza al futuro mercado de trabajo, esto sin dejar de lado el cultivo de las cualidades humanas, para que cada ser humano pueda establecer relaciones estables y eficaces con las personas.

Aprender a ser: esto consiste en el ejercicio de la autonomía y en la capacidad de juicio, por medio de un fortalecimiento de la responsabilidad personal, en una búsqueda del destino común. Por esto, no se tiene que ser indiferente a ninguno de los talentos que puedan estar escondidos en el ser mismo de la persona, talentos tales como la memoria, el raciocinio, la imaginación, las aptitudes físicas, el sentido de la estética, la facilidad para comunicarse con los demás, el carisma natural del dirigente. Para Delors (1996, p. 117) es necesario comprenderse mejor a sí mismo, expresa el papel que juega la educación en la formación humana como una contribución "al desarrollo global de cada persona: cuerpo y mente, inteligencia, sensibilidad, sentido estético, responsabilidad individual, espiritualidad".

Es indispensable que todo ser humano desarrolle un pensamiento autónomo y crítico, y un juicio propio, para determinar por sí mismos qué deben hacer en las diferentes circunstancias de la vida, es facilitar a la persona humana la libertad de pensamiento, el espíritu de iniciativa, la autonomía, libertad de juicio, de sentimientos y de imaginación, factores necesarios para que sus competencias alcancen su plenitud y sean artífices de su propio destino, al respecto Delors (1996) considera: 


\section{QGestión:}

[Número publicado el 30 de Junio del 2012]
Revista Cientifica Digital ISSN:2215-2288

URL:http:// revista digital.eae.fc s.uc r.ac.crl

Habrá que ofrecer a niños y jóvenes todas las oportunidades posibles de descubrimiento y experimentación, estética, artística, deportiva, científica, cultural y social (...) en la escuela el arte y la poesía deberían recuperar un lugar más importante que les concede. (p. 118)

Ante un mundo y una realidad cambiante, es necesario enfocar el fenómeno educativo como una realidad inscrita en la vida de las personas. La sociedad misma y sus diferentes transformaciones generan nuevos modos de ser y de actuar a los cuales la educación no les debe ser indiferente, nuevas formas de relación interpersonal surgen, rompiendo radicalmente con los esquemas tradicionales y exigen una mejor comprensión del otro, del mundo, un entendimiento mutuo, un diálogo pacífico y armónico, de todo esto está carente el mundo de hoy y sus sociedades.

Por otra parte Delors (1996), indica que es prioritario definir una educación adaptada a los diferentes grupos minoritarios, para que estos puedan asumir por sí mismos su propio destino. La educación debe por tanto esforzarse al mismo tiempo, por hacer consciente al individuo de sus raíces culturales, la formación en valores que le sirvan para ubicarse en el mundo de una forma solidaria, armónica y pacífica, de manera que las personas sean ciudadanos conscientes y activos de su comunidad.

El personal docente debe cumplir con una función de filtro, ante la sociedad de la información, los jóvenes que no son apoyados por sus familias o los movimientos religiosos, poseen y manejan un sinnúmero de información de las condiciones y situaciones presentes en el entorno de la población juvenil, por esto el personal docente tiene que adecuarse a su contexto, tener en cuenta esto y hacerse escuchar y comprender por los jóvenes, despertando en ellos el deseo de aprender y que el conocimiento exige esfuerzo, atención, rigor y voluntad, Delors (1996) indica lo siguiente:

La finalidad principal de la educación es el pleno desarrollo del ser humano en su dimensión social. Se define como vehículo de las culturas y los valores, como construcción de un espacio de socialización y como crisol de un proyecto común. (p. 59)

Es preocupante, que en los sistemas educativos actuales, la pobreza, el desempleo y la cantidad de excluidos socialmente aumenta considerablemente. Aún no se ha encontrado un 
modelo estructurador al respecto. Es así, que las sociedades están en crisis y muchos de sus ciudadanos condenados a la exclusión social.

El fenómeno educativo, va mucho más allá de ser un mero instrumento de información, de trasmisión de cultura y de ciencia. El fenómeno educativo se ha de conjugar en una relación de saberes diversos que deben converger en una unidad integral, trascendiendo los planteamientos académicos, centrándose en las personas, que conviven en sociedad.

La educación juega un papel importante, debe contribuir a que los estudiantes aprendan a descubrir aquellos aspectos de la sociedad que se deben transformar y discutir, buscando los medios necesarios para obtenerlo. Esto por medio de una sensibilización acerca de todo aquello que concierne a las injusticias sociales, la corrupción política y social que prolifera por doquier en sus respectivos contextos. En la era planetaria, se tiene que aprender a pensar y aprender a vivir conforme con las exigencias de ese proceso globalizado. Por estas razones, debe brindar alternativas para el mejoramiento humano y social. Es así, que es necesario reflexionar acera de la misión que posee la administración de la educación, como transformadora y promotora del cambio.

\section{Misión de la administración de la educación en el contexto actual.}

La administración de la educación, en la estructura educativa nacional, es esencial para el desempeño eficiente de las organizaciones educativas, tiene una importante responsabilidad para lograr la calidad del servicio que brinda, atiende diferentes procesos gerenciales inherentes a su función, que por su misma naturaleza son altamente complejos: la planificación, administración, supervisión y el control, son funciones que en forma articulada buscan la eficiencia en todos y cada uno de los procesos (Huérfano, 2009).

La administración de la educación se instituye como un proceso en el cual la planificación juega un papel trascedente, sobre todo en la fijación de una serie de metas encaminadas a poseer una organización institucional eficiente en cada una de sus estructuras que la conforman, desde este punto de vista la administración busca la eficiencia de los diferentes recursos materiales, humanos y financieros). Esto lo logra por medio de la dirección, el control y la supervisión de la educación. Como parte fundamental del quehacer educativo, y su función se encuentra determinada por su objeto de estudio; según Salas (2003, p.7) "la administración de la educación es una disciplina compleja que involucra lo educativo, lo 


\section{Gestión: \\ Giecocacon

[Número publicado el 30 de J unio del 2012]
Revista Cientifica Digital ISSN:2215-2288

URL:http:// revista digital.eae.fc s.uc r.ac.crl

administrativo y otras disciplinas, sin perder por ello su especificidad (nivel ontológico)"; es decir, la organización educativa está determinada por las ciencias de la educación y la teoría administrativa general; estas se constituyen en las piedras angulares de la administración educativa para responder a los retos y demandas que los contextos complejos demandan.

Es este nivel ontológico esencial en el análisis de todos aquellos aspectos relativos al quehacer y la praxis del profesional en administración de la educación, esencialmente en aspectos concernientes al manejo y gestión de los diversos procesos que a nivel administrativo educativo, burocrático y financiero se refiere. La administración de la educación desde esta perspectiva reflexiona y actúa en relación con el quehacer humano el cual se constituye en el objeto de estudio de la acción educativa y por ende el de la organización educativa.

Desde este punto de vista, y como la describe Huérfano (2009), la administración de la educación debe trascender los procesos internos, burocráticos y de gestión financiera, para abocarse con fuerza a la complejidad de lo humano en sus diferentes manifestaciones sociales, desde esta perspectiva no solo debe avocarse a los procesos de suministro de materiales, los aspectos burocráticos y control interno, evaluación y supervisión institucional, procesos de gestión financiera, mantenimiento, vigilancia entre otros, sino trabajar también con el recurso humano que posee.

La administración de la educación va más allá de todos estos procesos, pues esta también implica la dirección de la organización, un buen manejo estratégico de los recursos (humanos, tecnológicos, presupuestales, curriculares), la preparación de los docentes ante los diferentes retos y desafíos que el entorno complejo exige. El contexto actual, demanda de los profesionales en administración de la educación actualización constante, y un uso racional y estratégico de los recursos. Para Huèrfano (2009)

La administración escolar implica la dirección de la organización misma, el uso y ejercicio estratégico de los recursos, humanos, intelectuales, tecnológicos y presupuestales, la proyección de necesidades humanas futuras; la previsión estratégica de capacitación de los recursos humanos y la formación docente; la vinculación con el entorno; la generación de identidad del personal con la organización; la generación de una visión colectiva de crecimiento organizacional en lo colectivo y profesional en lo individual. (p. 1) 
Estos desafíos actuales, incluyen entre ellos, los conflictos entre los estudiantes en los centros educativos, según González (2009), la administración de la educación debe poner al servicio de toda la comunidad educativa todos los recursos que tenga a disposición para el logro de los objetivos propuestos para el mejoramiento del clima organizacional, de la administración del currículo, del recurso humano, con la finalidad de generar en la comunidad educativa experiencias positivas en relación con el aprendizaje, la convivencia, la comunicación y el desarrollo institucional. Para González (2009):

El director es la persona que debe organizar y coordinar la actividad principal del centro (gestionar tiempos, recursos, espacios, participación, etc.), al tiempo que se espera de él que muestre el camino a seguir para llevar a buen fin la actividad principal del centro que no es otra que la enseñanza y educación de los niños o jóvenes [...] es un agente encargado de cumplir y hacer cumplir las normas, instrucciones, órdenes y orientaciones que le llegan del Ministerio Central. (pp. 227-228)

En el nivel gerencial debe tenerse en cuenta que los conflictos pueden manifestarse a partir de dos vertientes según lo anota (Chiaventato, 1994) la acción antagónica entre dos o más personas, de orden intrapersonal (propios de su persona y emociones), y el otro el interpersonal (los que suceden entre un grupo de personas pertenecientes a una organización). Los conflictos suceden debido al antagonismo que hay entre las partes ya sea por conflictos de intereses.

La administración como un servicio público ha de enfocarse en la producción del conocimiento y del diseño de diferentes estrategias que coadyuven al mejoramiento de los procesos internos, tales como la enseñanza, el desarrollo integral de las personas. Esta tarea, no debe reducirse al simple trámite burocrático, debe enfocarse en las necesidades sociodemográficas que el contexto demanda y esto solo puede lograse si el personal directivo se preocupa por investigar, analizar y determinar todos y cada uno de los fenómenos que ocurren tanto a lo interno como a lo externo de sus organizaciones educativas.

Otro principio de la administración es que no debe servirse a sí misma, sino que debe estar al servicio del mejoramiento de la enseñanza. Tareas tales como evaluar la educación, promover proyectos, generar "visión", hacer que la organización se conozca 
a sí misma y se autoevalúe, evaluar, analizar si se fomenta la creatividad, los valores y el pensamiento crítico, apoyar administrativamente modelos pedagógicos y métodos didácticos, incorporar las nuevas tecnologías de información[...] son parte de las funciones de la Administración Educativa. (González, 2009, p. 1)

Las tendencias actuales de la administración de la educación exigen que los administradores y las administradoras de la educación sean consecuentes entre los objetivos propuestos y lo actuado, deben considerar la capacitación de su personal docente, de manera que adquieran las competencias necesarias para enfrentar los diferentes retos que la complejidad social requiere. Este personal debe ser un facilitador del cambio, para esto debe colaborar en brindar las herramientas necesarias para el manejo de los conflictos al personal docente, y en general a toda la comunidad educativa, de tal forma que los mismos se sientan capacitados para enfrentar los diferentes retos que a nivel social, cultural y humano se le presentan. Entre los que se destacan los conflictos estudiantiles. Al respecto, Minztberg (1991), citado por Blanco (2006), le atribuye al administrador una función de mediador de conflictos:

El administrador en su función directiva asume el rol de mediador de conflictos, es decir, debe responder a las presiones, dando solución y respuesta a conflictos inesperados; considerar de antemano toda contingencia, anticipar todas las consecuencias de las acciones que emprenden y obtener el consentimiento de los que integran la organización con el fin de lograr cooperación. (p. 17)

De esta forma para un abordaje eficiente de los conflictos por parte del personal directivo implica mucha dedicación y compromiso personal, sobre todo porque iniciar un programa para el mejoramiento de la comunicación, la motivación, la confianza y la generación de proyectos institucionales, que contribuyan al crecimiento humano y técnico del personal y al logro de la calidad educativa institucional. Esto es una tarea ardua, para la buena marcha de la institución, Además, generar proyectos que contribuyan al fomento de una convivencia sana entre los miembros de la comunidad educativa y sus diferentes vinculaciones con el contexto social inmediato.

La administración de la educación debe focalizarse ante todo en el recurso humano, este es su carácter ontológico. El personal directivo implementa una gestión de procesos para 
garantizar el desarrollo institucional, facilita procesos internos y externos que garanticen una convivencia sana, el desarrollo humano, la ética, el trabajo en equipo y los valores. Todo esto se logra con los principios fundamentales que toda estructura institucional debe poner en práctica, la planificación, organización, supervisión y evaluación de diferentes proyectos educativos de diseño y de rediseño que optimicen y garanticen el éxito en todos sus ámbitos.

\section{El conflicto como un fenómeno social complejo.}

Los conflictos forman parte de la cotidianeidad del ser humano, es decir, en la multiplicidad de intereses, motivaciones y relaciones, el conflicto aparece como un componente natural, sustancial e ineludible. Esto, sin embargo, no significa que por ser algo consustancial a la naturaleza humana, sea del todo negativo, pues existen variedad de conflictos, como formas de pensamiento, y estos deben de medirse de acuerdo a su magnitud y efectos. Es muy común, confundir el vocablo conflicto con la violencia; aunque ambos conceptos se relacionan entre sí, no representan lo mismo, como lo expone Cascón (2004):

Habitualmente, llamamos conflicto a la violencia directa, a la agresión [...] llamamos conflicto a lo que es la manifestación o consecuencia de conflictos mal abordados y peor resueltos. Los conflictos tienen su origen en las necesidades e intereses. Todas las personas tenemos necesidades: biológicas, económicas, ideológicas, afectivas, emocionales... mientras las de unos y unos pueden ser compatibles, no hay problema. El proceso del conflicto comienza cuando las de algunas personas no se satisfacen, cuando las de otras, originándose en una contradicción, un antagonismo que vamos a denominar problema. Su no resolución, o lo que es peor, el no afrontarlo, acaba llevándolos a una crisis que suele ser destructiva para quienes lo viven. (p. 25)

Es difícil determinar las causas que provocan los conflictos entre las personas, ya que el mismo se constituye una realidad de índole multicausal. Esto promueve el análisis de los conflictos estudiantiles que por su complejidad son objeto de un estudio interdisciplinario el cual debe determinar a partir de diferentes áreas sus causas y consecuencias aparte del impacto social que causa en el mundo y específicamente en las organizaciones educativas. Los conflictos y la violencia como problemáticas sociales emergen a partir de las condiciones del 


\section{Gegestion}

[Número publicado el 30 de Junio del 2012]

\section{Revista Cientifica Digital ISSN:2215-2288}

URL:http:// revista dig ita l.ea e.fc s.uc r.ac.cr/

contexto macrosocial, según sea la época en que se ubique. Se evidencian algunas causas que históricamente han provocado crisis de valores y que en la actualidad también la originan, por ejemplo está la situación de pobreza en la que viven muchas personas, las relaciones asimétricas entre las diversas autoridades estatales y los ciudadanos, los antagonismos sociales, la intolerancia racial, la cuestión política y económica como lo expone Rosas citado por Blanco, García, Grissi, Montes (2006):

La pobreza adquiere un carácter heterogéneo y complejo y no se refiere sólo a un conjunto de carencias materiales de diverso orden (económicas, falta de trabajo, de vivienda, protección social), sino también a las posibilidades culturales y simbólicas de poder ser partícipes, y a la vez, compartir, construir y proyectar valores sociales en términos de igualdad y justicia. (p. 23)

Los conflictos desde esta perspectiva deben visualizarse no un hecho aislado e individual, sino más bien, como un proceso, que tiene sus orígenes en la insatisfacción de diversas necesidades de índole, económica, religiosas, ideológicas, familiares y sociales, choques de tipo ideológico, político, o social, suelen provocar diversidad de problemas, la no resolución de estos, es lo que comúnmente provoca los conflictos. La siguiente figura ejemplifica los tipos de conflictos que existen y sus diferentes manifestaciones:

Figura 1

Tipología de los conflictos

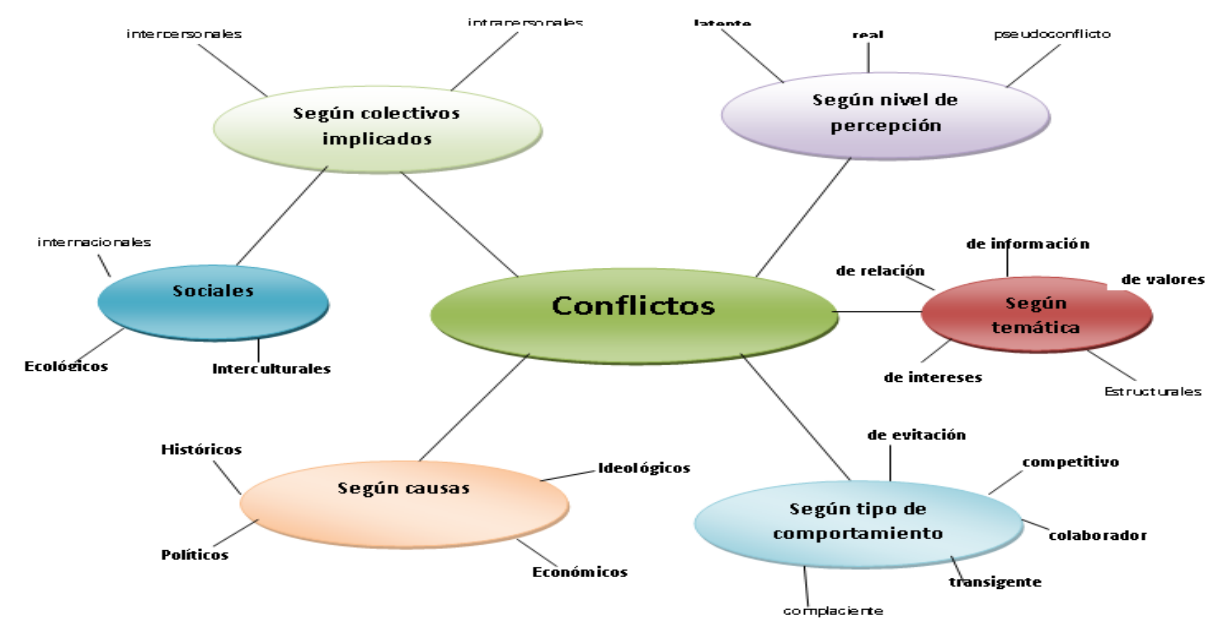

Fuente: Burguet, 1999, p. 22. 
En síntesis existen conflictos de diferentes tipos, estos deben ser analizados desde diversas perspectivas, acordes al contexto sociocultural en el cual se desenvuelven los sujetos. Es por esto que San Martín (2003), establece que uno de los elementos vitales de los conflictos son los protagonistas, de los cuales se desprenden cuatro tipos de conflictos: el intrapersonal (se da a lo interior de las personas); el interpersonal (el que sucede entre personas individuales; el intragrupal (el que sucede en el interior de un grupo, o institución), y por último el intergrupal (el que se origina entre diferentes grupos, o instituciones u organizaciones. Sobre este tema Cascón (2004) hace una llamado a no confundir el conflicto con la violencia:

Por otra parte la violencia se relaciona más con el uso de la fuerza física o psicológica, enfrentamientos con otras personas, falta de control emocional por parte de los sujetos que provocan heridas, abusos, humillaciones, daños físicos o materiales hacia las personas y la sociedad, y cuyas causas se remiten a la presión social y cultural, el discurso ideológico, la filosofía imperante, la economía, la política, la insatisfacción personal, el sentimiento de fracaso y rebeldía hacia el poder, entre otros. Es importante desde esta perspectiva no confundir el conflicto con la violencia, lo determina así: "una situación se define como conflicto no por su naturaleza externa, sino por su contenido, por sus causas profundas. (p. 8)

En relación con estos dos términos se deduce que a nivel organizacional educativo no solo se suceden conflictos, sino que muchas situaciones ocurren por la desatención, falta de prevención que termina en hechos violentos, esto se ejemplifican de diversas formas: destrucción infraestructura, agresiones físicas entre otras.

\section{Causas de los conflictos estudiantiles en las organizaciones educativas.}

Para identificar las causas de los conflictos en las organizaciones educativas, es necesario considerar todas aquellas situaciones en las que los estudiantes están involucrados o se involucran y que se constituyen en factores de riesgo, a nivel organizacional estos factores como lo estipula Fernández (2008), son de dos tipos: los de carácter endógeno y los de carácter exógeno. 
Los factores exógenos son que se relacionan con la parte exterior de la organización, es decir, todo lo que tiene que ver con el contexto social, la familia y la influencia mediática de los medios de comunicación, entre otros. Los factores endógenos o de carácter internos están relacionados con lo que pasa dentro de la organización educativa, son aspectos identificables, medibles, que se pueden prever y tratar; prevenir y actuar, entre ellos se destacan: los conflictos, la violencia, el clima organizacional, el currículo, la relaciones interpersonales, entre otros. Un factor exógeno que debe analizarse con cuidado es el contexto social.

El contexto social se constituye en un agente de mucha influencia, sobre todo por la estructura social o el modelo social que impera, desde esta perspectiva los focos de pobreza, el desempleo, la insatisfacción de las necesidades básicas, la condición socioeconómica, entre otras, propician de acuerdo con Fernández (2008), climas conflictivos, violentos y delincuenciales entre las personas, drogas, el alcohol, el aislamiento social y el status social. La escuela desde esta perspectiva, se convierte en depositaria de todo tipo de individuos y conductas.

La escuela se instrumentaliza como antídoto para esta avalancha de fenómenos sociales, pero no es la única respuesta a esta problemática. De hecho, el papel de modelado alternativo a las injusticias sociales que puede simbolizar la escuela se ve continuamente inhibido por la realidad vital del niño, en su entorno social y familiar. (Fernández, 2008, p. 32)

Por otra parte, agentes exógenos tales como los medios de comunicación se instituyen en algo significativo para la vida de los niños y las niñas y los jóvenes en la actualidad. Los medios de comunicación y las tecnologías de la información y la comunicación, especialmente, las redes sociales que se agrupan en estas plataformas tecnológicas ejercen mucha influencia en la forma de pensar y del actuar social, principalmente en su alcance y difusión, diversidad y dominio. Los programas televisivos actuales son muy llamativos para la población en general y la estudiantil en particular, los mismos están saturados de escenas conflictivas violentas, que son observadas por niños y niñas y adolescentes de diferentes edades, sin ningún tipo de discriminación, "la violencia se muestra asociada al poder y a la consecución de los deseos[...] la televisión actúa sobre la opinión pública conformadora de conciencia, orientadora de conducta y deformadora de la realidad" (Fernández, 2008, p. 33). Es justamente en la familia 
donde los niños, las niñas y jóvenes deben aprender a manejar una autonomía con responsabilidad. Este tipo de autonomía sugiere que los mismos aprendan a tomar decisiones y asumir las consecuencias de las mismas.

La familia, es el núcleo principal de formación y de socialización. Es la estructura fundamental para la formación en valores. Al mismo tiempo es forjadora de conductas antisociales y conflictivas en la sociedad, así lo establece Fernández (2008, p.35), "la familia es un elemento fundamental para entender el carácter peculiar del niño agresivo con conductas antisociales o conflictivas". La familia asumir un doble rol: convertirse en un agente formador de valores y de la prevención del conflicto, o todo lo contrario la disfuncionalidad familiar, los malos tratos, modelos de padres agresivos y violentos, los métodos de crianza inapropiados, estos factores son causantes de conflictos entre la población estudiantil.

Agentes endógenos causantes de conflictos estudiantiles.

Se denomina como factores endógenos a todos aquellos acontecimientos internos institucionales, provocan conflictos entre la población estudiantil. Entre estos factores de origen endógeno se destacan: los antivalores; la falta de docentes que sirvan de referente a los estudiantes y la desvalorización del sentido que tiene la institución como organización educativa, sus fines, su filosofía y sus valores, otros factores de carácter endógeno que contribuyen con los conflictos, según Fernández (2008):

Las discrepancias entre las formas de distribución de espacios, de organización de tiempos, de pautas de comportamiento [...] el énfasis en los rendimientos del alumno [...] la discrepancia de valores culturales distintos a los estipulados por la institución escolar [...] los roles del profesor y del alumno, que suponen un grado o nivel superior y otro inferior, creando una asimetría [...] las dimensiones de la escuela y el elevado número de alumnos, que impide una a tención individualizada. (pp. 36-37)

Desde este punto de vista la organización educativa, como estructura orgánica, puede favorecer o desfavorecer el aumento o la disminución de los conflictos estudiantiles, todo esto va a depender de la gestión que se realice en relación con los factores anteriormente mencionados, los cuales están directamente vinculados con el clima organizacional, las 
relaciones docente- docente; docente-alumno; personal directivo con los integrantes de la comunidad educativa, docente - padres y madres de familia. Otros factores de carácter endógeno a considerar en las instituciones y que pueden ser causa de conflictos son la ausencia de espacios para la participación estudiantil, la asimetría existente en la relación docente y población estudiantil las condiciones del proceso de enseñanza y aprendizaje y la organización curricular, de esta se desprende al mismo tiempo las metodologías utilizadas por los docentes, la organización del tiempo y el mantenimiento del orden dentro de las aulas, entre otros aspectos.

\section{Conflictos en las organizaciones educativas.}

El conflicto se genera, porque se origina un desequilibrio de poder, brota porque los jóvenes sienten la necesidad de prescindir de todos aquellos obstáculos relacionados con el poder y el uso de la fuerza, aspectos afines al empoderamiento de una persona sobre otra, sea el caso de un estudiantes versus un docente, o los docentes versus las direcciones, o también hombre versus mujer o viceversa, policía versus ciudadanía, padre, madre e hijos (as), docentes y alumnos, y entre ellos mismos. Las relaciones simbólicas que se generan entre las personas o grupos diversos, para Fernández (2008, p.43) refieren "la conflictividad escolar toma diferentes formas tales como disrupción, violencia entre iguales, agresiones profesor alumno, robos, etc.".

Los conflictos en los centros educativos suelen suceder de diversas maneras, es un problema multicausal, en los cuales intervienen diversos factores sociales que están íntimamente relacionados entre sí. Estos factores están íntimamente relacionados con el contexto social, y familiar se conjugan en conductas antisociales en los centros educativos, por los niños, las niñas y los jóvenes que en ellos estudian y en muchos casos perciben las normas establecidas en la institución y su misma situación económica algo injusto e inhumano, de allí que los mismos expresen esta insatisfacción de esta manera y lo toman como un conflicto personal. Así lo determina De Felippis, (2004):

Desigualdad, discriminación, humillación, injusticia, forman parte de un particular circuito de realimentación mutua que se despliega con las diversas formas de aceptación que 


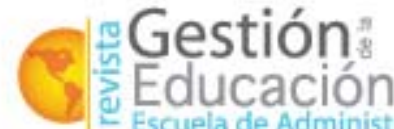 \\ Escuela de Administración Educativa}

[Número publicado el 30 de J unio del 2012]
Revista Cientifica Digital ISSN:2215-2288

URL:http:// revista dig ita l.ea e.fc s.uc r.ac.cr/

legitiman tanto desigualdad como las prácticas discriminatorias y a la vez invisibilizan los violentamientos. (p. 26)

El análisis del conflictos puede realizarse desde diferentes perspectivas o corrientes, estas delimitan el tipo de conflictos según sea su naturaleza y características; o también por sus alcances o fines. Entre estas corrientes se destacan: la tradicional, que afirma que los conflictos son una acción que debe evadirse, puesto que los mismos son indicadores de la disfuncionalidad del sistema, en aspectos relacionados con la comunicación, los valores, además, son un claro indicador de la incapacidad de los administradores y las administradoras de la educación en prevenir, detectar y afrontar las necesidades de sus subalternos. La de relaciones humanas que afirma que todo conflicto es inevitable en cualquier grupo. Su naturaleza, no es maligna, sino que deben convertirse en algo beneficioso para el grupo. La tendencia conceptual interactiva que postula que los conflictos son una fuerza positiva del grupo, y estos son un generador de acciones propositivas a favor del grupo. De Felippis (2004) argumenta, citando a Ortego (2006), que el desarrollo del conflicto está determinado en las siguientes cinco etapas:

- Incompatibilidad: en esta primera etapa elementos tales como: la comunicación, la estructura y las personas juegan un papel preponderante. Desde este punto de vista tergiversación de comunicados, comunicación deficiente, imposiciones e indiferencias pueden ser causas de conflictos entre los grupos humanos.

- La estructura: desde este punto de vista el estado físico, tamaño de la infraestructura, la carencia de comodidad, ambigüedad en las normas establecidas, falta de modelos, el estilo del liderazgo que se desarrolla, sistema de castigos y recompensas, pueden estimular al conflicto.

- Las variables personales: en esto factores personales, el sistema de valores institucional, las características de cada individuo, los diferentes caracteres y temperamentos, falta de control de sí, ausencia de inteligencia emocional, pueden ocasionar desacuerdos y desajustes en la gestión, y convertirse en conflictos.

- Conocimiento: un conflicto sucede en tanto cuanto una de las partes se ve afectada por la otra y se tiene conciencia de ello. Desde esta perspectiva el conflicto puede presentarse a partir de dos posiciones, ya sea como un conflicto percibido, ambas 
partes toman conciencia que existe un conflicto o que se están suscitando las condiciones para que ocurra; o como un conflicto sentido, en el cual se involucran las emociones, que pueden provocar en los individuos, depresión, ansiedad, pesimismo o frustración. Tomar conciencia de los hechos es trascendental en esta etapa.

- Intenciones: estas intervienen entre las percepciones y las emociones de los sujetos, las mismas suponen la forma en que el conflicto se va abordar, y la intencionalidad que poseen las personas en esto. La prevención del conflicto en esta etapa es importante.

- La conducta: es la parte visible del conflicto, que se torna en conductas agresivas, conflictivas y hasta violentas, esto por medio de acciones, reacciones y actos. En esta etapa el manejo de conflictos es esencial.

La última etapa tiene que ver con los resultados y las consecuencias; estas pueden ser de naturaleza positiva o negativa, todo depende como se hayan abordado las etapas anteriores. Desde este punto de vista, se indica que el conflicto puede producir crecimiento en la organización o un retraso, pueden ser un conflicto funcional (constructivo, propositivo, creativo e innovador), o disfuncional (negativo, causante de pesimismo y de problemas, causante de crisis y desorden) entre otros.

Desde esta perspectiva, no resolver un conflicto, o el abordaje incorrecto de un conflicto a nivel educativo, se convierte en un acto agresivo que vulnera o denigra la integridad: física, moral o psicológica de cualquier individuo. Es importante que las organizaciones educativas se preocupen por prevenir este tipo de situaciones conflictivas, tomando en cuenta que en las organizaciones educativas coexisten distintos tipos de conflictos; sus consecuencias habitualmente son de índole negativa como por ejemplo la disrupción, los problemas de disciplina (conflictos entre profesores (as) y alumnos (as), abuso de poder, falta de comunicación o ausencia total, maltrato físico y psicológico entre compañeros (bullying), vandalismo y daños materiales, violencia física (agresiones y extorsiones), y el acoso sexual. Estas situaciones vividas en algunas organizaciones educativas deben ser afrontadas, analizadas y comprendidas por parte del personal directivo quien posee la responsabilidad de asumir las decisiones que considere pertinentes para el abordaje de estas situaciones conflictivas en la institución. 
De Felippis (2004) afirma que entre las principales causales de los problemas en los estudiantes dentro y fuera de las organizaciones educativas están: la amenaza explicita, es cuando el docente de una forma directa o el discurso conlleva algún tipo de desagravio por parte del docente o un acto de represión; amenaza velada, es cuando el discurso del docente implica algún tipo de represalia expresada de forma sutil, a los estudiantes; asimetría cultural es cuando la comunicación se produce por distintos canales y distintos códigos lingüísticos. Esta asimetría puede ser de tipo grupal, esto cuando algunos o todos (as) los y las protagonistas pertenecen a un grupo, ya sea grupo de amigos y amigas, pandillas entre otros; discriminación es cuando el mensaje lleva implícito algún mensaje diferenciador o discriminatorio; descalificación: esto ocurre cuando el discurso, los gestos, denotan algún tipo de desacreditación o desautorización por parte del docente, llegando inclusive a humillar al estudiante; injusticia es cuando se comete algún tipo de injustica por parte del docente a los estudiantes y la ambiental, es cuando entra en juego el entorno sociocultural, como un factor que desencadena algún tipo de manifestación y conducta violenta.

\section{Proceso de gestión en las organizaciones educativas.}

Los procesos de gestión en las organizaciones educativas están directamente vinculados con todas y cada una de las diferentes acciones, actividades e iniciativas relacionadas con el abordaje, la prevención y el tratamiento de los diferentes conflictos que en la institucional-Surgen en a convivencia diaria de la población estudiantil. Desde este punto de vista y más específicamente, los procesos de gestión organizacional son la forma en que la organización visualiza, aplica, sanciona aquellos conflictos internos y externos a la institución, en que están involucrados los y las integrantes de la organización educativa.

Al mismo tiempo, tiene que ver con todo lo que la institución se realiza en procura de una disminución paulatina de estas situaciones, ya sea por medio de una toma de decisiones eficaz, mediación de los conflictos y capacitaciones varias, cuyos propósitos están encaminados no solo a erradicar los conflictos, sino prevenirlos y provocar una transformación personal y organizacional.

A partir de esto, el concepto de administración y el de gestión son objeto de innumerables discusiones en torno a su especificidad, complementariedad y similitud, "(...) esto significa que pueden existir prácticas administrativas sin que haya prácticas de gestión. En las 
prácticas de gestión la característica fundamental es la transformación que hace el sujeto, en este caso la persona humana" (Botero, 2009, p. 1). Es revelador enfatizar que como parte del objeto de estudio de la gestión es el sujeto en sí mismo, como ejecutor de acciones, transformador de su contexto y de sus relaciones con los otros sujetos. Para Botero (2009):

La acepción de gestión educativa está estrechamente relacionada con el concepto convencional de gestión administrativa. Como una aproximación se presenta esta definición: la gestión educativa se concibe como el conjunto de procesos, de toma de decisiones y realización de acciones que permiten llevar a cabo las prácticas pedagógicas, su ejecución y evaluación. (p. 2)

Desde esta perspectiva, la administración de la educación debe encargarse de gestionar, las prácticas pedagógicas, y todos aquellos programas preventivos, que colaboren con la transformación social e individual. La gestión educativa debe concentrarse en tres aspectos : el fomento de la autonomía (institucional y del sujeto), en la resolución de las diversas situaciones que se les presenten en cada una de sus áreas, tanto a lo interno como a lo externo de la organización; fomentar la democracia, esto tiene que ver con la participación e información en la medida de los posible de los procesos de toma de decisiones institucionales, facilitar los espacios de participación a cada uno de los miembros de la comunidad educativa.

La educación se convierte en un agente de mediación de la democracia, que se fortalece a sí misma en las organizaciones educativas, por medio de un adecuado proceso de toma decisiones en las que participe toda la comunidad educativa. En lo que concierne a la gestión de los conflictos estudiantiles es substancial aclarar que no existe un estilo único de gestión, sino múltiples estilos, cada uno de ellos está íntimamente relacionado con el estilo de gestión administrativa que el personal directivo realiza, desde esta perspectiva San Martin (2004) los plasma de la siguiente forma:

Los caminos normales para la gestión de los conflictos se concretan en cinco estilos. En el fondo corresponden a los estilos de dirección de la reja de Blake y Mouton: dirección burocrática (1.1) (dejar hacer); dirección relacionada (1.9) (paternalista) y dirección integrada (9.9) (catalítica). (p. 24) 


\section{Giestion:

[Número publicado el 30 de J unio del 2012]
Revista Cientifica Digital ISSN:2215-2288

URL:http:// revista digita l.eae.fc s.uc r.ac.cr/

Cada uno de estos estilos responderá de forma diferenciada los conflictos que a nivel institucional se presentan. Desde esta perspectiva determina cinco estilos diferentes para la gestión de los conflictos: La competición (yo gano/tu pierdes) según esto lo que impera en este estilo son los intereses personales, pasar por encima del otro sin importar las consecuencias, se imponen los criterios por medio de la persuasión, intimidación, la firmeza y el control; la acomodación (yo pierdo/tú ganas), es un estilo de gestión de tipo paternalista, evita sobre todo la confrontación y con ella las tensiones que la situación puede ocasionar. Se prefiere ceder a los deseos de la otra parte sin importar los propios; la evasión: (yo pierdo/ tú pierdes), este estilo es acorde a la administración de estilo burocrática. Esto significa dejar que las cosas sucedan evadiéndose las situaciones y los problemas. Lo que caracteriza a este estilo de gestión es la evasión de los conflictos (San Martín, 2004).

Por último, está la calidad, un concepto muy general, en el sentido de la diversidad de significados y aplicaciones que se le da, pero que generalmente están relacionados con los procesos de gestión curricular, de enseñanza y aprendizaje y las diferentes metodologías que se utilizan a nivel educativo para un buen desempeño de la institución, también incluyen la planeación de capacitaciones que coadyuven a la formación docente y al mejoramiento de sus servicios educativos. Un centro educativo eficiente es aquel que fomente la calidad en sus servicios, debe ser garante que tanto a lo interno como a lo externo, se realiza un debido proceso ante las diferentes situaciones conflictivas que se presenten.

El personal directivo de la educación en la gestión de los conflictos estudiantiles.

El personal directivo en su rol de gestor de los conflictos debe poseer una serie de competencias relacionadas con la planificación, control, organización, supervisión y evaluación de los diferentes acontecimientos de carácter endógeno y exógeno relacionados con los conflictos estudiantiles, así lo determina Blanco (2006, p.6) "el directores (as) es una persona clave en la generación, desarrollo y desenlace de acciones, por eso su activa participación debe tender al alcance de la meta de la organización".

Los directivos administrativos deben ser un ejemplo en mediación, también líderes de la transformación organizacional y comunal; asimismo, ser promotores del cambio y la transformación institucional. Este liderazgo transformacional es una de las competencias 
básicas que debe poseer en la actualidad para un ejercicio eficiente de sus funciones. Así lo describe Burguet (1999):

Proponemos defender la terminología de gestión/regulación de conflictos por encima de la resolución porque responde con mayor coherencia a la convicción de que no todos los conflictos se pueden resolver, hablar de conflicto permite incluir todo tipo de tratamiento que puedan recibir, incluyendo la prevención. (p. 21)

Gestionar los conflictos implica no solamente la elaboración de un plan de acción para la prevención de los mismos; tampoco se trata de una conversación tranquilizante entre las partes involucradas. Gestionar los conflictos implica la programación de una serie de procesos. Cada uno de estos procesos deben estar adecuados cada de ellos a la naturaleza del o los conflictos, el tipo de conflictos y el tipo de personas involucradas en ellos. Desde esta perspectiva los conflictos pueden ser confrontados de forma multidisciplinaria; no se trata de un plan remedial de las organizaciones educativas, más bien es un proyecto integral y permanente dentro del cual deben estar involucrado todo y cada de los miembros que pertenecen a la comunidad educativa, como lo considera Redorta (2004):

Hablar de "gestión de conflictos" es situarnos en la traducción de la expresión inglesa conflict management. Es entrar en un campo donde las definiciones no concuerdan y donde a menudo se habla de conflict resolution para referirnos a la misma cosa [...] no hay una definición precisa del concepto de gestión y resolución de conflictos [...] El concepto de gestión de los conflictos lo trataremos desde la perspectiva de la intervención. Sea o no resolución de conflictos, lo que nos interesa es qué hacer en situaciones concretas desde el punto de vista de quien es llamado, sin hallarse involucrado en el mismo, para manejar ese conflicto. O, también, en la perspectiva de cómo manejar más eficientemente los conflictos en los que nos hallamos implicados. (p. 36) 


\section{Gestion:}

[Número publicado el 30 de Junio del 2012]
Revista Cientifica Digital ISSN:2215-2288

URL:http:// revista digital.eae.fc s.uc r.ac.cr/

Desde esta perspectiva el concepto de gestión de los conflictos se diferencia notablemente del concepto resolución de los conflictos. En el nivel educativo gestionar los conflictos está más relacionado con la intervención de los conflictos. Esta intervención no solo implica la resolución de los mismos; la gestión en sí misma trasciende este tipo de acciones y busca ir más allá, puesto que el conflicto es en sí mismo un fenómeno complejo y multicausal. El siguiente cuadro ejemplifica el proceso a seguir en la gestión de los conflictos:

Figura 2

Contínuo de métodos de gestión de conflictos

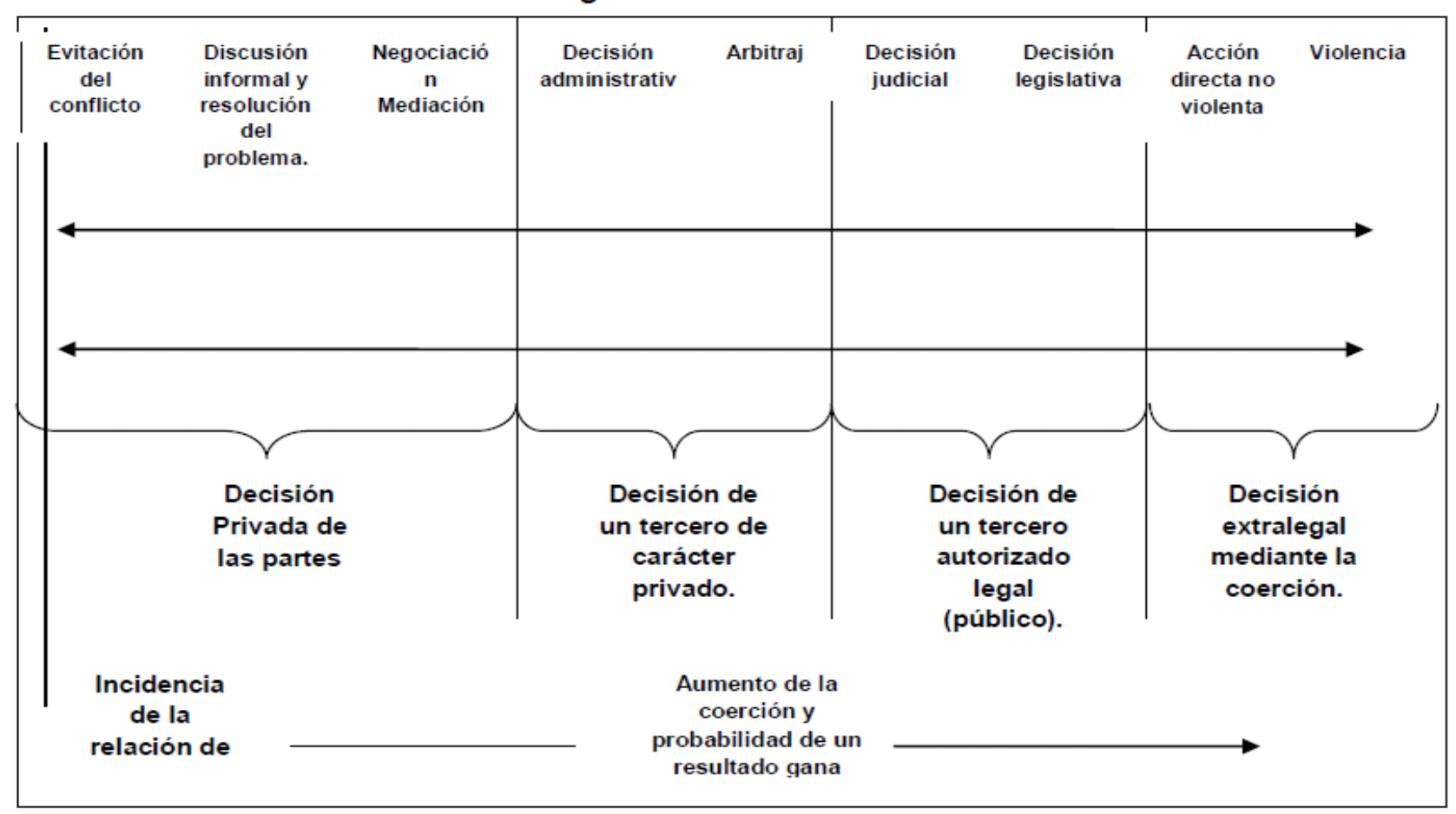

Fuente: Moore, (1986), adaptado por Redorta, (2004)

Desde esta perspectiva gestionar los conflictos para el personal directivo significa, la evitación de los conflictos, la discusión informal y resolución de los problemas, tomar decisiones administrativas, el arbitraje, la toma de decisiones, medir las consecuencias de los hechos, tomar en cuenta la parte judicial y legislativa, entre otras cosas. Es indispensable para una buena gestión de los conflictos que el personal directivo posea no solo un conocimiento básico 
en relación con la naturaleza de los conflictos y a violencia estudiantiles, sino poseer las competencias necesarias para un abordaje eficaz y constructivo de los mismos. Entre las competencias básicas que todo administrador debe poseer se encuentran: tener un panorama claro de la organización que dirige, es decir, conocer todos y cada uno de los componentes que la integran (estructura, personal, cultura organizacional, contexto).

Con base en esto, se debe elaborar un plan de acción para el abordaje de los diferentes conflictos que a nivel institucional se presenten. Componentes claves de este diagnóstico institucional están, la mediación, participación y la observación de las diferentes situaciones que se presentan tanto a lo interno como externo de la organización educativa. Una vez que el director o la directora posee un panorama claro acerca de lo que institucionalmente ocurre, comienza la segunda fase del proceso de abordaje de los conflictos estudiantiles: la planificación. Esta segunda fase consiste en el análisis de las diferentes situaciones relacionadas con los conflictos entre los estudiantes desde una perspectiva objetiva.

Otro componente fundamental en este proceso es el control de las diferentes situaciones que a nivel organizacional se presentan. Dentro de esta fase el desarrollo de un programa para la prevención y el abordaje positivo de los conflictos, es trascendental. La resolución pacífica de los diferentes conflictos, se constituye en una estrategia de control por parte del personal administrativo en las organizaciones educativas. Como parte de este proceso está la organización de las diferentes estrategias de prevención, intervención y resolución de los conflictos estudiantiles. Para este debe poseer una variabilidad de alternativas viables para la intervención, estas deben estar enmarcadas en lo que se denomina como el proceso de gestión institucional.

\section{Pilares básicos para la gestión de los conflictos en las organizaciones educativas.}

La educación por sí misma debe colaborar en el desarrollo integral de los niños, las niñas y jóvenes, desde esta perspectiva es importante subrayar que el trabajo en equipo con la comunidad educativa es sustancial para el ogro de estos propósitos. Entre otras cosas la mejora del clima escolar debe considerase como una necesidad institucional, fijarse unos objetivos comunes, para establecer un proyecto educativo debe constituirse en pilares básicos no solo en lo que a gestión curricular se refiere, sino también en la gestión administrativa institucional. 
San Martín (2003) considera cinco pilares básicos a nivel escolar para una adecuada gestión de los conflictos escolares: la comunidad educativa, que está conformada por todos los miembros que de forma directa o indirecta se relacionan con la organización, padres y madres de familia, estudiantes, docentes, direcciones entre otras. Desde esta perspectiva la compenetración entre las partes es fundamental, sobre todo para el logro de los proyectos que se quieren alcanzar, sobre todo colaborar a que el alumno pueda crecer en madurez en cada una de sus dimensiones como ser humano, la importancia de una comunidad educativa unida y democrática es vital, así lo considera San Martín (2003, p.64), "la creación de un ambiente educativo, participativo y democrático en nuestros colegios es la base ideal para facilitar la implantación de la cultura de la gestión de conflictos, y de la mediación escolar".

El proyecto educativo institucional es el punto de partida para el establecimiento de una cultura de gestión de los conflictos, su objeto central debe ser la persona del alumno o la alumna y su desarrollo integral. Debe estar estructurado en diferentes áreas, ya sea de gestión, intervención, recursos y acciones. Debe estructurarse sobre la base de unas metas y los lineamientos que se tienen que seguir para el logro de las mismas. Debe además crear conciencia a nivel institucional sobre aquellos valores que han fundamentarlo y concretarse a nivel curricular (por medio de diversas estrategias, entre ellas los temas transversales), al mismo tiempo debe de fomentar la visión que debe tener de los mismos, y por último ser el punto de referencia en lo que a calidad educativa y evaluación se refiere.

Los órganos colegiados son todas aquellas instancias que poseen algún tipo de injerencia de forma directa o indirecta en las decisiones institucionales, de manera que por orden jerárquico deben de involucrarse en los programas de gestión de los conflictos estudiantiles, las asociaciones de desarrollo comunal, las Juntas de Padres, comités de padres de familia; las direcciones y coordinaciones administrativas y curriculares, comité de valores, el gobierno estudiantil, la asamblea de representantes, y las directivas de clase, entre otras. Por otra parte, deben también incentivar la creatividad en la búsqueda de soluciones; el fomento en la formación de gestores y mediadores de los conflictos, y por la búsqueda de recursos, espacios, procesos y la economía de cada una de las iniciativas que se realizan. Los reglamentos internos (macro-políticas y micro- políticas de acción): la elaboración de un reglamento para la gestión y mediación de los conflictos, que colabore con la reducción de los mismos y al mismo tiempo fomente la convivencia entre todos los integrantes de la comunidad educativa. 
De acuerdo con Palazón citada por San Martín (2003), este reglamento según se estructura con base en tres principios, en el debe estar contempladas todas las normas de convivencia: consenso (participe a toda la comunidad educativa); el consentimiento (de todas las partes, tomar en cuenta las diversas opiniones, debe ser aceptado por todos); y por último el conocimiento, es decir difundir y divulgar el programa a nivel organizacional, y local

\section{Tipo de investigación}

Esta investigación es de carácter cualitativo, de acuerdo con Debus (1994, p. 3) "la investigación cualitativa es formativa, obtiene respuestas a fondo acerca de lo que las personas piensan y sienten, permite comprender las actitudes, motivos y comportamientos de la población en estudio". Asimismo, la investigación cualitativa para Debus (1994, p. 18), "se fundamenta en la fenomenología y la teoría interpretativa... Las finalidades comprender e interpretar la realidad, los significados de las personas, perspectivas, interacciones y acciones. En cuanto a la relación sujeto - objeto es de dependencia ya que se afectan mutuamente".

\section{Diseño de la investigación: método fenomenológico.}

Este diseño se caracteriza por su flexibilidad, ya que estudia a los sujetos en su contexto, en sus vivencias cotidianas, en su interacción con el medio, llegando a una comprensión del escenario mediante diferentes técnicas de interacción y de diálogo. Lo que se pretende es comprender las diferentes conflictos, sus formas habituales de hablar, de vivir, sin hacer por parte del investigador ningún juicio de valor al respecto, "el investigador cualitativo observa todo como si fuera la primera vez, no da nada por sobreentendido [...] no busca la moralidad o la verdad sino la comprensión minuciosa de las perspectivas de otras personas. Es expresar lo que ellos sienten, vivencian [...] sus anhelos, sus frustraciones, sus deseos, sus no concreciones..." (De Felippis, 2004, p. 17). Por esto, el diseño que se va emplear para efectos de esta investigación es el fenomenológico.

Para la elección de la población se determinó incorporar a personas y a una institución que se relacionarla directa o indirectamente con el problema y/o objeto de estudio, (adolescentes y adultos), el tipo de muestreo utilizado según Buendía, Colás y Hernández (1998) es intencional; es decir, este asume que la cultura y el contexto son comunes, 


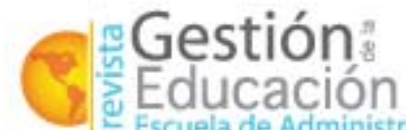

[Número publicado el 30 de Junio del 2012]
Revista Cientifica Digital ISSN:2215-2288

URL:http:// revista dig ita l.ea e.fc s.uc r.ac.cr/

reflejándose prácticamente en todas las personas, que se caracterizan por tener una participación directa o indirecta con los conflictos tanto a lo interno como a lo externo de la institución. Para esto, el Departamento de Orientación del centro educativo de educación secundaria en estudio realizó una selección estratégica de las personas para la elaboración de la investigación, estudiantes cuyas conductas habían sido conflictivas tanto a lo interno como a lo externo de la institución y otros cuyas conductas fueron propositivas.

El primer segmento estuvo constituido por las autoridades institucionales, personal docente y administrativo (director (a), docentes), estos se instituyeron en funcionarios competentes que trabajan para el Ministerio de Educación Pública (MEP), de donde se emitieron todas las directrices, lineamientos, reglamentos y programas educativos nacionales. Para efectos de esta investigación el director es clave para la comprensión del fenómeno; asimismo, los y las docentes que laboran en la institución y un orientador con muchos años de experiencia dentro de la organización.

El segundo segmento correspondió a los y las estudiantes. En este caso se realizaron grupos focales con estudiantes, tanto de sétimo como de undécimo nivel. Sus percepciones son esenciales para obtener información concerniente a la gestión del conflicto que se realiza a nivel institucional. De la población total de 1.000 estudiantes, aproximadamente, se trabajó con 18 estudiantes seleccionados por los orientadores de sétimo y quinto nivel, sus edades oscilaban entre los 14 y los 18 años.

\section{Descripción de las técnicas metodológicas empleadas.}

\section{Técnicas grupales.}

Es la reunión de dos o más personas que interaccionan frecuentemente, se reconocen como parte del grupo, que aceptan las mismas normas, que tengan temas de interés en común, que se identifiquen por un mismo modelo, que rijan sus conductas y que expresen sus ideas. Las técnicas grupales son un conjunto de procedimientos que se utilizan para lograr con eficiencia las metas propuestas. Entre las técnicas grupales que Barrantes (1999) indica que se pueden utilizar en la investigación cualitativa, pueden nombrarse varias: actividades recreativas, asambleas, conferencias, congresos, técnicas demostrativas, discusión en grupos pequeños, 
dramatizaciones, grupos de encuentro, grupos de sensibilización, seminario, socio drama, talleres, entre otros.

En esta investigación se tomó como técnica la discusión en grupos pequeños que de acuerdo con Barrantes (1999) se caracteriza por ser un intercambio mutuo de ideas y de opiniones. También, permite el máximo de acción y de estimulación recíproca entre los integrantes, porque se le otorga responsabilidad a los participantes en las diversas actividades y se les enseña a pensar como grupo y desarrollar un sentido de igualdad. Esta técnica puede utilizarse para identificar y explorar los diversos tópicos de discusión, o problemas comunes de los que forman el grupo y es de mucha utilidad porque proporciona y difunde información y conocimientos, para motivar al grupo para que actúe y cristalice sus pensamientos.

\section{Grupo focal.}

Esta técnica fue útil para la interacción entre la población participante, puede fomentar respuestas más interesantes o nuevas e ideas originales, sirve de medio de orientación para desarrollarse de manera natural y espontánea.

La presión de los grupos es valiosa para promover sus reflexiones y dilucidar opiniones contrarias; los temas por discutir son abiertos para evitar que los participantes den respuestas neutras o no proporcionen cierta información. Según Debus (1994, p.13) "los grupos focales aprovechan la dinámica de grupo y permiten a un grupo pequeño de participantes ser guiadores por un moderador calificado para alcanzar niveles crecientes de comprensión y profundización de las cuestiones fundamentales del tema objeto de estudio".

\section{Entrevista semiestructurada.}

Esta técnica permite al investigador y al informante poder entablar un diálogo, sin ningún tipo de condicionamiento, haciendo de esta técnica algo parecido a una conversación entre amigos. Su objeto "es que los participantes hablen sobre las cosas que les interesa y extraer contenidos sobre la forma en que los participantes utilizan sus propios conceptos y términos" (Buendía, Colás y Hernández, 1998, p. 236). De igual forma, Erlandson y otros, citados por Valles (2007, p.179) en dicen: "las entrevistas pueden adoptar una variedad de formas, incluyendo una gama desde las que son muy enfocadas o predeterminadas a las que son muy 
abiertas...". Esta entrevista se caracteriza por ser semiestructurada, es decir, es guiada por un conjunto de preguntas y cuestiones básicas a explorar sin un orden predeterminado. En ella se utilizará una grabadora de audio, se le explica al estudiante el porqué de la grabadora y la confidencialidad de la información.

El análisis de la información se realizará mediante la triangulación metodológica. Esta técnica consiste en la combinación de diferentes estrategias de recolección de la información obtenida de los sujetos para ir relacionando de acuerdo a su coincidencia en las formas de percibir el problema objeto de estudio, "es la combinación en un estudio único de distintos métodos o fuentes de datos" (Valles, 2007, p. 54). La triangulación es el modo en que el investigador confronta y somete a control recíproco relatos de diversos informantes, observaciones de otros tipos y fuentes de datos, se obtiene una comprensión más profunda y clara del escenario, de las personas estudiadas y su proceso. El tipo de triangulación que se utilizará será la triangulación metodológica que según Mucchielli (1996, p. 348) consiste en: "recorrer con diversas técnicas de recogida de datos para obtener formas de expresión y de discursos variados: observaciones, entrevistas, dibujos, producciones de textos escritos. Al mismo tiempo este tipo de triangulación hace uso de la técnica de entrevista particular semiestructurada y los grupos focales como fuentes de datos".

\section{Objetivos, categorías e indicadores metodológicos.}

\section{Objetivo general.}

- Analizar la gestión de los conflictos estudiantiles en el Liceo de Costa Rica.

\section{Objetivos específicos.}

- Determinar la percepción del personal docente y administrativo, y los estudiantes con respecto gestión de los conflictos que se realiza nivel institucional.

- Identificar factores protectores y de riesgo asociados al contexto sociocultural juvenil.

- Identificar los tipos de conflictos estudiantiles que se suceden en la institución.

- Determinar los procesos de micro políticas y macro políticas internas que se generan en la institución en relación con los conflictos estudiantiles. 
Tabla 1

Definición de las categorías

\begin{tabular}{|c|c|c|c|}
\hline Categoría de Análisis & Definición Conceptual & $\begin{array}{l}\text { Definición } \\
\text { Operacional }\end{array}$ & Indicadores \\
\hline $\begin{array}{l}\text { Percepción de la } \\
\text { gestión de los conflictos } \\
\text { estudiantiles. } \\
\text { Indicadores: }\end{array}$ & $\begin{array}{l}\text { Se concibe la gestión } \\
\text { como el conjunto de } \\
\text { procesos, de toma de } \\
\text { decisiones y realización } \\
\text { de acciones que } \\
\text { permiten llevar a cabo } \\
\text { las prácticas } \\
\text { pedagógicas, su } \\
\text { ejecución y evaluación. } \\
\text { (Botero, 2009, p. 2) } \\
\text { El conflicto estudiantil } \\
\text { son “aquellas } \\
\text { situaciones de disputa o } \\
\text { divergencia en las que } \\
\text { hay contraposición de } \\
\text { intereses (tangibles), } \\
\text { necesidades y/o valores } \\
\text { en pugna... (Cascón, } \\
2004, \text { p. 6) }\end{array}$ & $\begin{array}{l}\text { Se entiende como } \\
\text { gestión del conflicto } \\
\text { estudiantil a los } \\
\text { procesos y actividades } \\
\text { que a nivel } \\
\text { administrativo se } \\
\text { realizan para la toma de } \\
\text { decisiones y el abordaje } \\
\text { de los conflictos } \\
\text { estudiantiles, presentes } \\
\text { en la organización } \\
\text { educativa en el Liceo en } \\
\text { estudio. }\end{array}$ & $\begin{array}{ll}\text { - } & \text { Procesos de } \\
\text { intervención } \\
\text { - } & \text { Normativas } \\
\text { institucionales. } \\
\text { - } \text { Programas para la } \\
\text { gestión y } \\
\text { prevención d los } \\
\text { conflictos } \\
\text { estudiantiles. } \\
\text { Capacitaciones } \\
\text { relacionadas con el. } \\
\text { tratamiento de los } \\
\text { conflictos }\end{array}$ \\
\hline $\begin{array}{l}\text { Tipos de conflictos } \\
\text { estudiantiles. }\end{array}$ & $\begin{array}{l}\text { El conflicto estudiantil } \\
\text { se define como aquellas } \\
\text { situaciones de disputa o } \\
\text { divergencia en las que } \\
\text { hay contraposición de } \\
\text { intereses (tangibles), } \\
\text { necesidades y/o valores } \\
\text { en pugna. (Cascón, } \\
2004, \text { p.6) } \\
\text { Los más frecuentes son } \\
\text { de origen familiar, lucha } \\
\text { de clases, guerra entre } \\
\text { estados, luchas por el } \\
\text { poder político, } \\
\text { ideologías, intereses } \\
\text { profesionales, } \\
\text { marginación, lingüística, } \\
\text { racial. (Blanco, 2006) }\end{array}$ & $\begin{array}{l}\text { Los conflictos } \\
\text { estudiantiles están } \\
\text { relacionados con todas } \\
\text { aquellas conductas, } \\
\text { acciones, o actividades } \\
\text { en que participan los } \\
\text { estudiantes de forma } \\
\text { disruptiva, } \\
\text { irrespetuosos, } \\
\text { amenazantes o } \\
\text { humillantes, que } \\
\text { provocan diferentes } \\
\text { tipos de problemas } \\
\text { tanto a lo interno como } \\
\text { a lo externo de la } \\
\text { organización y que } \\
\text { pueden causar algún } \\
\text { tipo de daño ya sea de } \\
\text { tipo moral, físico o } \\
\text { material a sus pares y a } \\
\text { personas ajenas a la } \\
\text { institución; y que son } \\
\text { provocados ya sea a } \\
\text { nivel individual o grupal } \\
\text { (pandillas) conformadas } \\
\text { por estudiantes del } \\
\text { Liceo de Costa Rica. }\end{array}$ & $\begin{array}{l}\text { - } \text { Conductas de los } \\
\text { estudiantes } \\
\text { - } \quad \text { irrespeto a la } \\
\text { autoridad, } \\
\text { - Daños a la planta } \\
\text { física. } \\
\text { - Agresiones a } \\
\text { estudiantes y } \\
\text { docentes (peleas. }\end{array}$ \\
\hline
\end{tabular}




\begin{tabular}{|c|c|c|c|}
\hline Categoría de Análisis & Definición Conceptual & $\begin{array}{c}\text { Definición } \\
\text { Operacional }\end{array}$ & Indicadores \\
\hline $\begin{array}{l}\text { Factores protectores y } \\
\text { de riesgo asociados al } \\
\text { contexto sociocultural } \\
\text { juvenil. }\end{array}$ & $\begin{array}{l}\text { El contexto sociocultural } \\
\text { es el conjunto de } \\
\text { valores, modas y pautas } \\
\text { que construyen los } \\
\text { jóvenes dentro de un } \\
\text { marco histórico y } \\
\text { temporal determinado. } \\
\text { Incluye en este sentido } \\
\text { los mitos, la historia, las } \\
\text { creencias, los miedos, } \\
\text { los ídolos, que } \\
\text { caracterizan y } \\
\text { conforman los } \\
\text { elementos constitutivos } \\
\text { de la juventud, es decir } \\
\text { la Identidad personal, } \\
\text { social y cultural de los } \\
\text { adolescentes. [...] los } \\
\text { diferentes modos o } \\
\text { formas de interacción } \\
\text { que se expresan a } \\
\text { través de actos o } \\
\text { conductas que por la } \\
\text { acción u omisión }\end{array}$ & $\begin{array}{l}\text { Los estudiantes } \\
\text { pertenecen a un } \\
\text { contexto cultural } \\
\text { particular. Este contexto } \\
\text { al mismo tiempo está } \\
\text { inserto en otro más } \\
\text { amplio, y que se } \\
\text { convierten en factores } \\
\text { de riesgo en la } \\
\text { gestación de conductas } \\
\text { conflictivas en el cual } \\
\text { aspectos tales como la } \\
\text { pobreza, la sociedad de } \\
\text { consumo, la política, la } \\
\text { deserción y el fracaso } \\
\text { escolar, temperamentos } \\
\text { los e comunicación, } \\
\text { entre otros ejercen una } \\
\text { influencia directa en los } \\
\text { comportamientos de los } \\
\text { jóvenes, sobre todo en } \\
\text { las diferentes } \\
\text { problemáticas sociales } \\
\text { Los Factores } \\
\text { protectores son los }\end{array}$ & $\begin{array}{l}\text { - } \text { Factores de riesgo } \\
\text { asociados a la } \\
\text { familia, a la } \\
\text { violencia y al } \\
\text { - } \quad \text { contexto social. } \\
\text { - Uso de drogas } \\
\text { - } \quad \text { Deserción } \\
\text { estudiantil. }\end{array}$ \\
\hline \multirow[t]{2}{*}{ Categoría de Análisis } & Definición Conceptual & $\begin{array}{c}\text { Definición } \\
\text { Operacional }\end{array}$ & Indicadores \\
\hline & $\begin{array}{l}\text { ocasionan un daño cuyo } \\
\text { origen es la } \\
\text { representación del otro } \\
\text { como objeto implican la } \\
\text { configuración de la } \\
\text { relación. (Blanco, } 2006 \text {, } \\
\text { p. 14) }\end{array}$ & $\begin{array}{l}\text { aspectos del entorno o } \\
\text { competencias de las } \\
\text { personas que favorecen } \\
\text { el desarrollo integral de } \\
\text { individuos o grupos y } \\
\text { pueden, en muchos } \\
\text { casos, ayudar a } \\
\text { transitar circunstancias } \\
\text { desfavorables. } \\
\text { (Ministerio de } \\
\text { Educación, Ciencia y } \\
\text { Tecnología de } \\
\text { Argentina. }\end{array}$ & \\
\hline $\begin{array}{l}\text { Macro-políticas y micro- } \\
\text { políticas institucionales } \\
\text { relacionados con la } \\
\text { gestión de los conflictos } \\
\text { estudiantiles. } \\
\text { Indicadores: }\end{array}$ & $\begin{array}{l}\text { En el seno de la macro } \\
\text { política escolar, } \\
\text { delimitada por las } \\
\text { relaciones existentes } \\
\text { entre el Estado, la } \\
\text { Administración y la } \\
\text { sociedad civil; a la vez } \\
\text { que (de) su dimensión } \\
\text { micro política, } \\
\text { determinada por las }\end{array}$ & $\begin{array}{l}\text { Desde esta perspectiva } \\
\text { la institución y su } \\
\text { funcionamiento está } \\
\text { determinada por otras } \\
\text { instancias sociales } \\
\text { económicas y políticas } \\
\text { macro, siendo la } \\
\text { institución educativa } \\
\text { reproductora (micro) de } \\
\text { estos poderes y el }\end{array}$ & $\begin{array}{l}\text { Reglamentos y } \\
\text { directrices } \\
\text { emanados por el } \\
\text { Ministerio de } \\
\text { Educación Pública. } \\
\text { Lineamientos y } \\
\text { directrices } \\
\text { emanados por la } \\
\text { dirección } \\
\text { académica y }\end{array}$ \\
\hline
\end{tabular}




\begin{tabular}{|c|c|c|c|}
\hline Categoría de Análisis & Definición Conceptual & $\begin{array}{l}\text { Definición } \\
\text { Operacional }\end{array}$ & Indicadores \\
\hline & $\begin{array}{l}\text { relaciones, por igual } \\
\text { peculiares, entre } \\
\text { profesores, currículo y } \\
\text { estructuras } \\
\text { organizativas (Beltrán, } \\
\text { 1991, citado por Jares } \\
\text { 1995, p. 11) }\end{array}$ & $\begin{array}{l}\text { director y los (as) } \\
\text { docentes ejecutores de } \\
\text { las normativas } \\
\text { impuestas, esto está } \\
\text { relacionado con las } \\
\text { practicas más concretas } \\
\text { que se realizan en la } \\
\text { institución, que están } \\
\text { relacionadas con el } \\
\text { poder que se ejerce ya } \\
\text { sea desde las } \\
\text { autoridades del } \\
\text { Ministerio de Educación } \\
\text { Pública, en el aula, } \\
\text { entre profesor y alumno, } \\
\text { en la familia entre } \\
\text { padres e hijos, sobre } \\
\text { todo enfatiza la } \\
\text { influencia que ejercen } \\
\text { este tipo de micro } \\
\text { políticas }\end{array}$ & $\begin{array}{l}\text { colaboradores. } \\
\text { Manuales para la } \\
\text { convivencia. }\end{array}$ \\
\hline
\end{tabular}

Fuente: Elaboración propia (2010).

\section{Principales hallazgos}

Los hallazgos han sido numerosos, en lo que compete al área de gestión administrativa tanto el administrador y como del equipo de orientadores poseen una conciencia clara entorno a la problemática que hay a nivel institucional en relación con los conflictos estudiantiles. Esto se evidenció en la entrevista realizada a la dirección, en la que se indica, que no solo existen conflictos, sino que hay manifestaciones de violencia ya sea entre estudiantes de la misma institución y con los de otras instituciones educativas cercanas. Asimismo, se expresa que se están haciendo las gestiones pertinentes tanto a nivel interno, como externo con diferentes autoridades para la disminución de los conflictos estudiantiles. No obstante, el análisis de la información reflejó que la existencia de iniciativas referidas a la gestión de los conflictos por parte de la dirección y el Departamento de Orientación, pero estas se encuentran únicamente relacionadas al diálogo, la aplicación del Reglamento de Disciplina, y de vez en cuando algún tipo de capacitación. No se evidenció un programa o proyecto relacionado con la gestión de los conflictos ya sea de tipo preventivo o de un enfoque positivo. 
Según el director, la problemática de la institución es compleja, a lo interno suceden diversas situaciones que provocan conflictos entre los estudiantes, con respecto de esto el director expresó: "al existir poca tolerancia entre ellos, robos, y otras situaciones, los estudiantes explotan... hace falta más trabajo en el ámbito de la formación de valores, tenerles una concepción más humana como personas, abocarse más en el contexto en el que viven sobre todo porque sus familias son muy disfuncionales" (Entrevista director institucional, 2010), según esto las circunstancias y el contexto del cual están y se desenvuelven los estudiantes del Liceo de Costa Rica, es problemático. Asimismo, estudiantes considerados líderes y modelos institucionales al respecto dijeron: es que muchas veces no se puede hacer nada porque aquí es un colegio en que..., digamos no pueden meter a los estudiantes a la clase porque el colegio está abierto, tampoco los pueden expulsar porque diay los estudiantes que hacen eso son los que no vienen a clases entonces los expulsan a ellos no les importan" (Grupo focal estudiantes sétimo nivel, 2010). Al respecto, Darino y Gómez (2007) señalan que:

El conflicto ignorado: Dificultades que no se presentan como tales para los actores institucionales. Ejemplo deserción, calidad de los aprendizajes. El conflicto se elude: es percibido, pero se evita que aparece explicitado. Aparecen situaciones de malestar bajo la forma de rumores. El conflicto se redefine y se disuelve: A veces el conflicto no se resuelve pero se aprende a pesar del mismo, porque el contexto se ha modificado. El conflicto se elabora y se resuelve: Analizar los procesos, plantearlos, negociar y tomar decisiones consensuadas según el contexto. (p. 20)

Se corroboró por medio de las entrevistas, que hace falta trabajar más en equipo del personal directivo con sus respectivos departamentos, y los (as) docentes parecen que cada uno trabaja por su parte. Tanto los (as) docentes como los estudiantes manifestaron su insatisfacción con el tipo de gestión que se está realizando. Los sujetos consideraron insuficientes las acciones, ya que a pesar de que poseen una buena imagen del Director (muy dialogante y conciliador), le hace falta una mayor presencia en la organización educativa, sobre todo en la gestión de programas que colaboren con la gestión de los conflictos y la violencia estudiantil, ser más enérgico en la toma de decisiones, tener un mayor control de lo que a nivel interno y externo ocurre, ser menos de escritorio y más de pasillo, tener un mayor control del 
ingreso de los estudiantes, sobre todo del ausentismo escolar, tanto de estudiantes como de docentes.

En torno a los conflictos estudiantiles que se presentan a nivel institucional, tanto el director académico, los orientadores, los (as) docentes y estudiantes coincidieron en su mayoría en que los tipos de conflictos que se dan a nivel organizacional están relacionados con las discusiones, peleas en la calle, agresión física, el vandalismo, pandillerismo, conflictos con la autoridad, faltas de respeto, ya sea con los (as) docentes o con otros agentes externos tales como la policía y civiles; peleas con estudiantes de otras instituciones educativas; conflictos por mujeres; la intolerancia, entre otras. A pesar de esto por parte del Orientador entrevistado, sus impresiones revelaron que a nivel interno todo está bajo control.

Tanto docentes como estudiantes manifestaron su descontento por las diferentes problemáticas que a nivel interno como externo ocurren, sobre todo los estudiantes de sétimo se quejaron del abuso que sufren por parte de algunos estudiantes de quinto año, estos los acosan constantemente y chantajean con el dinero e inclusive hasta con sus corbatas y el uso del uniforme, al respecto también se manifestaron conflictos relacionados con esto. Los estudiantes se quejan del ausentismo de los (as) docentes y estos igualmente se quejan que algunos estudiantes llegan al Liceo no necesariamente a clases. Durante la visita a la organización se evidenció la presencia de muchos estudiantes tanto dentro como fuera de la organización. Asimismo, en un determinado sector: las paredes, las puertas de los pasillos y los baños rayados con diferentes símbolos o grafitis.

Otro de los factores considerado como generador de conflictos, por parte de los estudiantes estuvo relacionado con el trato y la metodología de enseñanza empleados por los (las) docentes. Los estudiantes manifestaron que las clases son aburridas, y los (las) docentes en muchos casos muy imperativos e indiferentes. Desde esta perspectiva los estudiantes consideraron al Director muy pasivo ante estas situaciones, esto le resta respeto por parte de ellos. Por otra parte, un aspecto en el que coincidieron la mayoría de los estudiantes de la muestra es que los (as) docentes debieron cambiar la metodología con la que enseñaron, ya que la misma es causa de aburrimiento, desidia y desmotivación para asistir a los cursos. Las clases según ellos son aburridas, carecen de otras alternativas (videos, salidas fuera) que les inviten (a los estudiantes) a interesarse por la materia, sus métodos fueron muy tradicionales, lecturas del libro de la materia y hacer sus correspondientes ejercicios, así lo evidenciaron la población en estudio de quinto nivel: "porque algunos profesores fueron como aburridos, no 
intentan la clase bien, no se les entiende bien, no explican mucho...Tienen que ser más dinámicos, más... Cambiar la rutina, siempre dicen siéntese, saquen el libro y saquen el cuaderno, dictado, explican, tarea y vámonos; no, más dinámico qué sé yo, ver un video, ir a ver... que si estamos viendo instituciones públicas ir a ver una institución, por ejemplo que si vamos a ver algo de francés bueno ver un poquito más de la cultura" (Grupo focal estudiantes de quinto año, 2010), otro al respecto expresó: "pero sí pienso que tenemos que cambiar, tenemos que hacer otro tipo de educación; a nosotros los mayores nos acostumbraron a un tipo de enseñanza y estamos muy arraigados a eso y los muchachos viven otro mundo y nos hemos dado cuenta y no hacemos nada." (Entrevista docente, 2010).

EI XI Informe del Estado de la Educación de Costa Rica (2005), evidencia este tipo de situación de la siguiente forma:

La metodología, los contenidos de los cursos, sus objetivos y las formas de evaluación son distintos a los que encararon durante la primaria. Estos factores hacen que las y los jóvenes se sientan inseguros, e incluso experimenten ansiedad, ante el imperativo de vincularse con una nueva institución y un nuevo grupo de compañeros. Todo ello sucede al tiempo que inician un proceso de grandes cambios individuales asociados a la adolescencia [...] Una educación poco atractiva: un último factor desde el punto de vista estudiantil es que las y los jóvenes encuentran poco atractiva y a veces hasta "sin sentido" la educación secundaria. Encuestas realizadas entre desertores del sistema revelan que la mayoría no puede precisar el aporte que obtuvo en la escuela, ni sabe qué le hubiera gustado encontrar mientras permaneció en el sistema. (p. 69)

Los estudiantes manifestaron también que para muchos y a nivel social por la imagen que posee el Liceo el llevar el uniforme en la calle les es conflictivo, la gente los miran mal, y en algunos establecimientos la seguridad no les quita los ojos de encima, e inclusive sin tener que ver con los problemas de otros estudiantes del Liceo, cuando caminan por la calle estudiantes de otras instituciones buscan algún tipo de pleito, solo por el hecho de portar el uniforme del Liceo. Ellos consideraron que la imagen de los estudiantes del Liceo se ha estereotipado como negativa, esto mediatizado por las informaciones que brindan los medios de comunicación colectiva. El director sabe de estas problemáticas; sin embargo, consideró que esto es un 
problema histórico del Liceo con otras instituciones, y las situaciones en el Liceo se resuelven de forma inmediata, utilizando el diálogo como herramienta.

Por otra parte, el contexto sociocultural es el medio dentro del cual los estudiantes han nacido, crecen y se desarrollan en la actualidad. El contexto sociocultural está directamente relacionado con la composición familiar, su funcionalidad y disfuncionalidad. Por otra parte, los sujetos -tanto el director como los orientadores y docentes- coincidieron en que el contexto del cual proviene la mayoría de los estudiantes es complejo y difícil, caracterizado por tener niveles muy altos de violencia; con respecto a sus familias todos coincidieron en que la mayoría de los jóvenes provienen de familias disfuncionales, ya sea por cuestiones de desintegración familiar, violencia doméstica presente en el hogar, o la indiferencia que presentan muchos padres de familia en relación con el proceso educativo de sus hijos. Otro factor que recalcaron los sujetos en relación con el contexto sociocultural es que en su mayoría los estudiantes provienen de barrios muy conflictivos de las zonas periféricas de San José (La Carpio, San Sebastián; Desamparados; Los Guido, Guadalupe; y Alajuelita, entre otros. La mayoría provienen de estratos sociales muy bajos, caracterizados por altos índices de pobreza, padres desempleados y otros privados de libertad.

Entre otros conflictos más frecuentes según los estudiantes, estuvieron las confrontaciones personales, los denominados pleitos personales, los estudiantes considerados líderes en el Liceo expresaron que sí ocurren pleitos fuera de la institución, los cuales se dan en las inmediaciones de Plaza Víquez, así lo describieron: "en el mismo Liceo, cuando son broncas con otro Colegio es simple y sencillamente porque uno pasó y lo 'enjacharon' y el otro no se dejó y después se hizo una bronca", (Grupo focal estudiantes de quinto año, 2010). Este tipo de conflictos es tipificado por Darino y Gómez (2007, p. 15) como conflictos grupales "un grupo con identidad propia siente lesionado sus intereses frente a otro grupo mayoritario en que sus acciones no tienen en cuenta las necesidades de las minorías. Un grupo piensa que otro invade sus competencias". Con respecto de esto otro estudiante expresó lo siguiente: "aquí lo que hay es violencia... la violencia del Liceo se da cuando hay un pleito con otro Colegio, eso es lo que siempre pasa, que alguien tiene un problema con otro de otro Colegio y se van cientos de personas que no lo conocen" (Grupo focal estudiantes de quinto año, 2010). Con respecto de esto el director opinó: “al Liceo cuesta que vengan estudiantes de otras instituciones pero los del Liceo sí van a cualquiera, pareciera que es una cuestión también relacionada con la masculinidad, género..." (Entrevista director, 2010). 
Por su parte, los estudiantes expresaron que en sus barrios los conflictos y la violencia son algo común, todas las semanas suceden acontecimientos relacionados con estos fenómenos, los mismos afirmaron la situación problemática en que están diariamente en contacto. Asimismo, manifestaron en su mayoría la poca o casi nula preocupación de sus padres con respecto de su proceso de enseñanza. Un dato interesante y que no hay que dejar de lado es la ubicación geográfica en que se encuentra la institución en estudio. El Liceo se halla en una zona céntrica, cerca de Plaza González Víquez, es aquí donde en su mayoría se desarrollan los conflictos, ya sea peleas entre los mismos estudiantes o con otros estudiantes de otras instituciones educativas. La cercanía relativa con otras instituciones tales como el Liceo del Sur, el Colegio Napoleón Quesada y el Vocacional Monseñor Sanabria de Desamparados, favorece en gran medida el desarrollo de los conflictos. Por otra parte, la misma estructura del Liceo colabora con esto pues está estructurado por dos edificios casi idénticos separados por un bulevar público, esto obliga a que un gran número de estudiantes estén constantemente cruzando la calle de un edificio a otro sin ningún tipo de control y rozándose ya sea con personas civiles, autoridades u otros estudiantes. Los estudiantes en su mayoría concordaron en que esta situación geográfica causa conflictos. Esto favorece al mismo tiempo el trasiego de drogas, la delincuencia y el vandalismo, entre otras situaciones. Al respecto, San Martín (2003) indica que:

Agentes tales como: la pobreza, la marginación, el desempleo, la falta de expectativas profesionales, son problemas sociales que originan con frecuencia problemas de agresividad, delincuencia y conductas antisociales. La cultura de la competitividad, la agresividad social, los extremismos políticos y sociales, el racismo y la xenofobia, son elementos presentes en la sociedad, estos favorecen los conflictos sociales, la búsqueda de lo fácil, del placer del alcohol, de la droga y otros sucedáneos son también factores que contribuyen a crear ese clima de conflictividad. (p. 37)

En el Liceo hay muchas paredes rayadas, asimismo, en algunas clases pupitres y puertas rayadas, los estudiantes al respecto reconocieron que estas acciones suceden a lo interno de la organización: "en sí los estudiantes las rayan, aparte de que eso es delincuencia, actos delictivos, porque es vagancia y no ponen respeto en la casa de ellos... ellos vienen a las 


\section{Giestion: \\ Escuela de Administración Educativa}

[Número publicado el 30 de J unio del 2012]
Revista Cientifica Digital ISSN:2215-2288

URL:http:// revista digital.eae.fc s.ucr.ac.cr/

instituciones a hacer lo que no pueden hacer en la casa, a jugar de vivos y empiezan con mates así y después están metidos en un problema, y ellos no hacen eso" (Grupo focal estudiantes de sétimo año, 2010), otra de las docentes con respecto de esta problemática expresó: "se dicen ser liceístas pero no lo demuestran. Hay muchos que se dedican a poner el nombre, vulgaridades..." (Entrevista docente, 2010).

Al respecto la población en estudio de quinto ante esta problemática dijo: "aquí al principio de año está todo pintado, los baños limpios sin rayar, al día siguiente usted entra al baño y otra cosa: rayado, todo sucio... Simplemente rayan la pared y un recordatorio para todos los que lo vean..." (Grupo focal estudiantes de quinto año, 2010). Esta misma situación el orientador del Liceo, opinó que los que realizan este tipo de acciones fueron estudiantes que no asisten con regularidad a clases, y da a entender que le sobra el tiempo para hacer este tipo de cosa, lo que se puede observar es que a nivel interno no existe algún tipo de control para evitar este tipo de acciones "yo he conversado con ellos, aducen que si bien hay estudiantes que no entran a clases, aprovechan esos tiempos para rayar de símbolos" (Entrevista a orientador, 2010). Con respecto a esto, Carbonell y Peña (2001, p. 36) explican que entre las conductas antisociales y disruptivas que son consecuencias de los conflictos y la violencia en los centros están: "las conductas disruptivas: agresiones esporádicas, hurtos y robos esporádicos, pequeños destrozos en edificio material... actos vandálicos en el propio centro".

Según lo dicho por Carbonell y Peña (2001), el vandalismo se considera como un acto de agresión y de violencia, es evidente que el administrador educativo, como parte de su proyecto de gestión de los conflictos invite a los integrantes de la organización educativa al cuido y mantenimiento de la planta física y sus activos, por parte de toda la comunidad, educativa. Esto significa crear conciencia especialmente en los estudiantes, con respecto de que ni las paredes ni los pupitres deben rayarse o dañarse, pues son parte del patrimonio nacional.

En lo que compete a la micropolítica institucional, esta se ubica en la aplicación interna que hace la organización educativa encabezada por su director en torno a los reglamentos y disposiciones que el Ministerio de Educación Pública demanda. En esto tienen que ver con otras disposiciones y decisiones que se toman a nivel institucional para el abordaje y la prevención de los conflictos estudiantiles, ya sea por medio de programas para la prevención, el currículo u otras actividades organizadas por el equipo interdisciplinario para la resolución de los conflictos estudiantiles. 


\section{Giestion: \\ Escuela de Administración Educativa}

[Número publicado el 30 de Junio del 2012]
Revista Cientifica Digital ISSN:2215-2288

URL:http:// revista dig ita l.ea e.fc s.uc r.ac.cr/

En este caso, según el director de la institución, en caso de conflictos, peleas, vandalismo entre otros, en el Liceo se aplica las medidas correctivas estipuladas en el Reglamento de Disciplina del MEP; sin embargo, de acuerdo con el caso se utiliza otro recursos, que a la postre de acuerdo con él es muy efectivo: el diálogo entre las partes, la dirección adopta en estos caso el rol de mediador y realiza el arbitraje correspondiente, según sea la situación. El director no mencionó algún tipo de abordaje en conjunto con el equipo de orientadores. Estos al mismo tiempo afirman que ellos poseen un programa para la intervención de este tipo de situaciones.

Como lo describe Sarason citado por Blase (2002), son las relaciones de poder las que determinan las micropolíticas:

Las escuelas y los sistemas escolares son organizaciones políticas en las que el poder es una característica organizativa. Ignorar las relaciones de poder y el sistema existente restará esfuerzos a la reforma. Esto ocurrirá, no porque haya una gran conspiración o una terquedad de mula para resistir al cambio, o porque los educadores simplemente adolezcan de falta de imaginación y creatividad (lo cual no es cierto), sino más bien porque reconocer e intentar cambiar las relaciones de poder, especialmente en instituciones tradicionales complejas, es una de las tareas más complicadas que los seres humanos podemos emprender. (p. 1)

La política de puertas abiertas del Liceo, esto de acuerdo con los (as) docentes y estudiantes es una de las principales causas de los problemas que suceden en la organización, ya que difícilmente se puede impedir el ingreso de otras personas ajenas al Liceo, es decir jóvenes que ya no están en él y llegan con el uniforme puesto, para los estudiantes muchos de los estudiantes revoltosos pertenecen a este grupo, y según los (as) docentes esto ocurre en la realidad. El director manifestó que esta política pertenece a la tradición del Liceo y es muy difícil quitarla, esto provocaría la rebelión estudiantil. La percepción que poseen tanto los estudiantes como algunos docentes es que las medidas disciplinarias que se toman en relación con los reglamentos son poco efectivas, en realidad no solucionan nada, al aplicarse el Reglamento. Los mismos estudiantes enfatizaron que en lo que respecta a la resolución de los conflictos hace falta mucho por hacer, es muy poco lo que ellos ven a nivel institucional. 
Por último, se encuentran las modificaciones curriculares, según los (as) docentes, orientadores y estudiantes la administración anterior metió a la fuerza el bachillerato internacional sin consultar a padres de familia y estudiantes, esto causó muchos conflictos y tensión entre los estudiantes, de acuerdo con ellos no se encontraban preparados, de allí las constantes situaciones que sucedieron hace dos años. Esta disconformidad aun la mantienen los estudiantes, a esto se le añade las intenciones que existen de introducir mujeres al Liceo en la actualidad.

\section{Conclusiones del estudio}

La comunidad educativa del Liceo está consciente de que tanto a lo interno como a lo externo de la institución existen situaciones relacionadas con los conflictos estudiantiles. Estos se manifiestan de formas diversas: conflictos entre estudiantes, con estudiantes, entre estudiantes y docentes, por último entre estudiantes del Liceo con otros estudiantes de otras instituciones y autoridades nacionales. Existió una preocupación real por parte de las autoridades sobre la situación en la que actualmente se encuentra el Liceo, en relación con las manifestaciones de los conflictos, sobre todo por la impotencia que sienten ante algunos acontecimientos relacionados con este fenómeno.

La percepción que tuvieron los sujetos en estudio con respecto de la forma en que se gestiona los conflictos fue divergente. Las autoridades reconocen que en el nivel institucional se abordan, aun la mayoría de la muestra reconoció que estas acciones fueron insuficientes. Lo que se evidenció es que en realidad no existe un programa institucional para la prevención e intervención de los conflictos estudiantiles. Una de las estrategias que en el nivel administrativo educativo se utiliza fue la mediación, para esto fue imprescindible el empleo del diálogo y el consenso entre las partes. Los estudiantes reconocen que a nivel interno se realizan acciones para combatir los conflictos estudiantes, asimismo, las consideraron insuficientes, además dijeron que ante estos acontecimientos, tanto la dirección como los docentes se han mostrado indiferentes.

En relación con la intervención de los conflictos es importante que las autoridades tomen conciencia de que es fundamental para el abordaje de estos el trabajo en equipo. Los esfuerzos organizacionales para la intervención de los conflictos estudiantiles, estos sin embargo, fueron esfuerzos aislados. La no existencia de un programa y de un comité que colabore con esto 
dificulta la labor. La institución cuenta con un equipo de orientadores y psicólogos para la gestión e intervención de las diferentes problemáticas que se presentan a nivel interno y externo. Cada uno de ellos de acuerdo con el análisis de los datos realiza diferentes acciones para el abordaje de los conflictos; sin embargo, no poseen un programa sistematizado de intervención y prevención de los conflictos. Asimismo, no se evidenció la existencia de un manual de procedimientos de este tipo de situaciones, ya que en algunos casos los orientadores dicen que ellos son los que intervienen. Ante esto, es prioritario que se construya un programa integral de gestión de los conflictos. La dirección debe informar a toda la comunidad educativa, los diferentes procesos, proyectos, y programas que a nivel institucional se implementan, esto incluye el reglamento de disciplina. De esta forma él se asegura de que la información llega a sus destinatarios.

\section{Recomendaciones}

Se recomienda a las autoridades administrativas y docentes del Liceo tomar conciencia de que no se trata de gestionar acciones solo cuando ocurre algún tipo de conflicto estudiantil, el dialogar con los estudiantes es importante, pero no es la única medida, por lo tanto, es importante que la organización educativa posea un plan para la prevención y el abordaje de los conflictos estudiantiles, puesto que este no existe. Para esto debe organizarse un comité institucional de carácter interdisciplinario cuya principal misión es la de proyectar un programa institucional para la gestión de los conflictos estudiantiles que contemple: la prevención, intervención e implementación de diversas acciones, actividades y dinámicas, cuyo único propósito será crear un clima de paz y de una sana convivencia entre todos los miembros de la comunidad educativa.

Es importante, por esto la búsqueda de otras alternativas correctivas, ya que para los estudiantes las boletas ya no cumplen con su función. Esto mismo debe inculcarse en los docentes sobre todo hacia aquellos que se muestran indiferentes ante este tipo de situaciones, y ni siquiera aplican el Reglamento. Los docentes deben tener claro sus funciones y deberes.

Es significativo que la dirección asuma un papel más protagónico en lo que respecta a la gestión de los conflictos estudiantiles, deben mantenerse los vínculos con los estudiantes, docentes, administrativos, y las autoridades del MEP. 
Asimismo, que se fomenten actividades de tipo lúdico y deportivo, esto porque según los estudiantes las instalaciones fueron utilizadas mayoritariamente por personas ajenas al Liceo. El estudiantado solicita que se realicen más actividades a nivel deportivo y lúdico.

Se recomienda que a nivel nacional se realice un simposio nacional en torno a experiencias exitosas en materia de gestión de los conflictos estudiantiles. En este simposio deben invitarse no solo a los directores (as) de las instituciones públicas y privadas de Costa Rica, también a expertos en sociología, psicología, derecho, entre otras. De tal forma que el tema sea abordado desde un enfoque interdisciplinario y transdisciplinario.

Los estudiantes demostraron poseer gran identidad con el Liceo, su historia y símbolos, y lo que significa estudiar allí, sin embargo, existe otro grupo de estudiantes que creen que esa identidad está relacionada con los conflictos históricos del Liceo, (peleas históricas con otros colegios), en defensa de lo que ellos denominan "hermandad liceísta". Por otra parte, los mismos estudiantes reconocen que se ha estereotipado una imagen negativa del Liceo, esto hasta el punto que a cualquier parte que vayan la gente los mira y señala como si fuesen a hacer algún tipo de daño. Por lo tanto, las autoridades del Liceo deben preocuparse por divulgar una imagen diferente del Liceo, sobre todo en aquellos aspectos en los cuales sobresalen, deportes, concursos de oratoria, ferias científicas, entre otros. Es innegable que el contexto educativo del cual provienen los estudiantes afecta directamente su comportamiento a un grupo numeroso de estudiantes, especialmente los que proceden de barrios conflictivos de San José.

Según esta investigación, la participación por parte de los padres de familia en la institución fue muy escasa. Deben fomentarse a nivel institucional una mayor preocupación y responsabilidad y sobre todo el rol que juegan por parte de los padres de familia. La institución cuenta con el personal técnico administrativo suficiente para coordinar y estructurar un programa de escuela para padres. Este tipo de iniciativas pueden colaborar con la gestión y la prevención de los conflictos. De acuerdo con este estudio la mayoría de los estudiantes e inclusive docentes reconocieron que las metodologías de enseñanza que se aplican son poco atractivas. A nivel administrativo deben realizarse las gestiones pertinentes para la revisión de las aulas, y las metodologías de enseñanza. Las clases monótonas provocaron que lo estudiantes se sintieran poco motivados a asistir a las lecciones, lo que al mismo tiempo indujo a muchos estudiantes a estar fuera de clases, convirtiéndose esta situación en un factor de riesgo para la generación de los conflictos al estar los estudiantes fuera de las aulas si hacer nada. 
La percepción de los estudiantes con respecto a los medios de comunicación fue negativa, en especial los principales noticieros y periódicos del país. Según ellos los medios informativos han fomentado una imagen muy negativa del Liceo, pues lo presentaron y presentan como una institución conflictiva y violenta, obviando por otra parte, aquellas actividades constructivas tales como los debates, la oratoria, y los desfiles del 15 de setiembre, entre otros.

Es importante que el director o la directora ejerzan su liderazgo, teniendo mayor presencia a nivel interno de la institución, (aulas, pasillos, y los patios). Debe además tener un mejor control del ingreso de personas en la institución. Para esto el comité debe trabajar en la construcción de una estrategia para evitar el ingreso de personas ajenas a la organización. Brindar cursos y capacitaciones para los estudiantes relacionados con la erradicación del machismo entre los estudiantes, y con esto fomentar valores tales como la tolerancia, la sana convivencia, el diálogo y la amistad. Esto aplica también para el personal docente, en lo que respecta al mejoramiento del clima organizacional y la relación con los estudiantes. Para esto debe organizar al personal docente y administrativo con respecto de la responsabilidad que conlleva el cuido de los recreos, pasillos y los baños. Esto incluye ir al patio exterior "bulevar", pues en él no se encontró a ningún docente y es allí donde se gestan la mayoría de los conflictos.

La institución posee suficientes instalaciones para el desarrollo del deporte y la recreación. La administración debe velar para que estas sean utilizadas en su mayoría por estudiantes. Asimismo, posee el material humano suficiente para organizar diversas selecciones, ya sea de fútbol, volibol, baloncesto, rugby, y hasta beisbol, e inclusive los concursos de oratoria, bandas, marchistas, entre otros. La administración institucional, debe velar para que se cambie la imagen mediática que la sociedad se ha hecho del Liceo. Para esto por recomendación de los mismos estudiantes, los medios deben publicar también las buenas acciones que se hacen a lo interno. Para esto el director debe convocar a los diferentes medios de prensa para que hagan reportajes frecuentes y así ir cambiando tanto la imagen interior como la exterior. Es imperativo innovar en opciones muy diferentes a las anteriores, que acaparen la atención.

Se concluyó que tanto a nivel interno como externo han sucedido diversidad de conflictos, entre los cuales se destacaron las peleas o riñas entre estudiantes del mismo Liceo y de otras instituciones; y otros conflictos por drogas y robos. Por otra parte, algunos de estos 
conflictos terminaron convirtiéndose en actos violentos. Es una realidad que los estudiantes de niveles inferiores del Liceo fueron intimidados por algunos estudiantes de niveles superiores, esta intimidación estuvo relacionada con la sustracción de pertenencias personales, dinero, corbatas entre otras situaciones. De la misma manera, las autoridades deben gestionar medidas pertinentes para fomentar una cultura de respeto por el patrimonio nacional. Para esto deben implementarse a nivel institucional La utilización de estrategias como los murales colectivos, boletines informativos, el periódico estudiantil, la Web entre otros pueden colaborar con la disminución de los conflictos y al mismo tiempo al involucrar a los estudiantes estos se conviertan en los principales portavoces.

De allí la importancia que cobra la introducción de cursos relacionados con la comunicación asertiva, la denuncia del acoso ya sea entre estudiantes o docentes -estudiantes entre otras situaciones. Estas problemáticas deben incluirse dentro del proyecto institucional. La administración educativa debe focalizar sus esfuerzos en la búsqueda de alternativas viables para la resolución pacífica de los conflictos, por medio del fomento de las habilidades sociales, (autoestima, asertividad, resiliencia, entre otras).

Fue evidente que las medidas disciplinarias que se han tomado (boletas), no mejoraron la conducta de los estudiantes; y otras que se toman no fueron eficientes en la solución de las diversas problemáticas relacionadas con los conflictos estudiantiles.

En los últimos tiempos hubo mucha inestabilidad en las direcciones del Liceo. Estas situaciones para el tipo de institución no son recomendables, sobre todo para su estabilidad y equilibrio, de allí la importancia que cobra que el MEP garantice la estabilidad en lo que a direcciones se refiere y no realice algún tipo de cambio en la administración actual. No se pudo comprobar la existencia de un programa o proyecto para la gestión de los conflictos estudiantiles. La dirección debe propiciar un plan para el desarrollo del mismo. Para esto cuenta con orientadores y psicólogos, los docentes y estudiantes.

Se recomienda al personal directivo velar porque se cumplan las normativas institucionales, sobre todo debe abocarse a tener una mayor presencia entre los estudiantes, y así irse ganando su respeto. Desde la administración educativa deben gestionarse todos los procesos concernientes a la prevención e intervención de los conflictos estudiantiles. Para esto el Ministerio de Educación y las universidades públicas implementar procesos para la capacitación en materia de conflictos. De igual forma las universidades públicas deberán incluir dentro de sus mallas curriculares este tipo de conocimiento y así capacitar a los futuros 
profesionales en la administración de la educación en estas áreas tan complejas. En este tipo de acciones el comité institucional para la gestión de los conflictos debe colaborar.

Es importante que a nivel administrativo se busquen otro tipo de sanciones (no represivas), para las diferentes faltas que cometan los estudiantes, y así garanticen que las mismas sean realmente efectivas y colaboren con el clima de paz. Debe instituirse un protocolo para el abordaje de los conflictos estudiantiles. Este debe ensayarse de vez en cuando, con esto se garantizará que la institución está preparada ante cualquier acontecimiento.

\section{Referencias bibliográficas}

Barrantes, R. (1999). Investigación: un camino al conocimiento. Un enfoque cuantitativo y cualitativo. San José, Costa Rica: EUNED.

Blanco, Y. (2006). Gestión directiva desde un enfoque de resolución positiva de conflictos en el Liceo Hernán Zamora Elizondo de Dulce Nombre de Coronado, durante el primer trimestre del curso lectivo 2006. Tesis para optar por el grado de Magister en Educación. Universidad de Costa Rica.

Blanco, M.; García, S.; Grissi, L. y Montes, L. (2006). Relaciones de violencia entre adolescentes. Influencia de la familia, la escuela y la comunidad. Buenos Aires: Espacio Editorial.

Blase, J. (2002). "Las micropolíticas del cambio educativo". Revista de curriculum y formación del profesorado, 6(1-2), 2002. http://www.ugr.es/ recfpro/rev61ART2.pdf

Botero, C. (2009). "Cinco tendencias de la gestión educativa". Revista hispanoamericana de Educación, 49(2), mayo 2009. Ediciones Organización de Estados americanos [OEA].

Buendía, L.; Colás, P. y Hernández, F. (1998). Metodología de la investigación en Psicopedagogía. Madrid: Mc Graw Hill.

Burguet, M. (1999). El educador como gestor de conflictos. Bilbao, España: Desclée De Brouwer.

Carbonell, J. y Peña, A. (2001). El despertar de la violencia en las aulas: la convivencia en los centros educativos. Madrid: CCS

Cascón, F. (2004). Apuntes sobre educar en y para el conflicto y la convivencia. Recuperado en: www.andalucíaeducativa.com

Chiavenato, I. (1994). Administración de recursos humanos. Colombia: Mc Graw Hill Interamericana, S.A.

Darino, M.S. y Gómez, M. (2007). Resolución de conflictos en las escuelas: proyectos y ejercitación. Buenos Aires: Espacio Editorial.

Debus, M. (1994). Manual para excelencia en la investigación mediante grupos focales. Washington, D.C.: Porter/Novelli.

De Felippis, I. (2004). Violencia en la institución educativa: una realidad cotidiana. Buenos Aires: Espacio Editorial.

Delors, J. (1996). La educación encierra un tesoro. Madrid, España: Santillana. 
Estado de la Nación. (2005). Universalización de la educación secundaria y reforma educativa. Recuperado en: http://www.oei.es/quipu/costarica/estado_educacion/cap_2_2.pdf

Fernández, I. (2008). Prevención de la violencia y resolución de conflictos. Madrid, España: Narcea.

George, C. y Álvarez, M. (2005). Historia del pensamiento administrativo. México: Pearson Educación.

González, C. (2009). Retos de la administración educativa. Recuperado en: www.congresoretosyexpectativas.udg.mx/Congreso

Huérfano, Z. (2009). Administración de la educación. Recuperado en: www.monografías.com

Morín, E. (2001). Los siete saberes necesarios para la educación del futuro. Barcelona: Ediciones Paidós Ibérica.

Mucchielli, A. (1996). Diccionario de métodos cualitativos en ciencias humanas y sociales. Madrid: Ed. Síntesis.

Redorta, J. (2004). Mediación: cómo analizar los conflictos. Barcelona: Paidós Ibérica.

Salas, F. (2003). "La administración educativa y su fundamentación epistemológica". Revista Educación, 27 (1), pp. 9-6.

San Martín, J. (2003). La mediación escolar: un camino para la gestión del conflicto escolar. Madrid: CCS.

Sagastizabal, M.A. Diversidad cultural y fracaso escolar. Educación intercultural: de la teoría a la práctica. Buenos Aires: Novecud.

Valles, M. (2007). Entrevistas cualitativas. Cuadernos metodológicos. Madrid: Centro de Investigaciones Sociológicas. 